\title{
The effect of feeding culture media with biogenetic precursors on high production of depsides in agitated shoot cultures of black and red aronias
}

\author{
Agnieszka Szopa $^{1}$ (D) $\cdot$ Paweł Kubica ${ }^{1}$ (D) $\cdot$ tukasz Komsta $^{2}$ (D) Aleksandra Walkowicz-Bożek $^{1} \cdot$ Halina Ekiert $^{1}$ (D)
}

Received: 16 January 2020 / Accepted: 11 June 2020 / Published online: 18 June 2020

(c) The Author(s) 2020

\begin{abstract}
Agitated shoot cultures of two aronias, Aronia melanocarpa (Michx.) Elliott and Aronia arbutifolia (L.) Pers., were maintained on Murashige \& Skoog medium (1 mg/l BA and $1 \mathrm{mg} / \mathrm{l} \mathrm{NAA}$ ), both with and without the addition of various biosynthetic precursors of phenolic acids and depsides (phenylalanine, cinnamic acid, benzoic acid and caffeic acid). Each substance was added in 5 concentrations $(0.1-10 \mathrm{mmol} / \mathrm{l})$, each concentration at two time points (at the beginning and on the 10th day of cultures). Twenty-four phenolic acids were determined in methanolic extracts of the biomasses collected after 20 days of growth cycles by means of HPLC method with DAD detection. The presence of seven compounds was confirmed in all the extracts-five depsides (neochlorogenic, chlorogenic, cryptochlorogenic, isochlorogenic and rosmarinic acids), and syringic and caffeic acids. The main metabolites in A. melanocarpa shoot extracts were isochlorogenic, chlorogenic and neochlorogenic acids (max. 249.88, 450.35, $192.16 \mathrm{mg} / 100 \mathrm{~g} \mathrm{DW}$ ). The main metabolites in A. arbutifolia shoot extracts were: chlorogenic, isochlorogenic and cryptochlorogenic acids (max. 361.60, 224.5, 526.2 mg/100 g DW). The largest total amounts of the compounds were confirmed in the cultures of both aronias after the addition of cinnamic acid (989.79 and $661.77 \mathrm{mg} / 100 \mathrm{~g} \mathrm{DW}$, respectively) and caffeic acid (854.99 and $1098.46 \mathrm{mg} / 100 \mathrm{~g} \mathrm{DW}$, respectively) at concentrations of $5 \mathrm{mmol} / \mathrm{l}$ on 10th day of growth cycles. These maximum amounts were 3.41, 3.42, 2.95 and 5.67 times higher, respectively, than in the control cultures. This is the first report documenting the high production of depsides in shoot cultures of black and red aronias after feeding with their biosynthetic precursors.
\end{abstract}

\section{Key message}

The influence of feeding culture media with biogenetic precursors on high production of depsides in agitated shoot cultures of Aronia melanocarpa and Aronia arbutifolia was proved.

Communicated by Wagner Campos Otoni.

Electronic supplementary material The online version of this article (https://doi.org/10.1007/s11240-020-01869-4) contains supplementary material, which is available to authorized users.

Agnieszka Szopa

a.szopa@uj.edu.pl

$\triangle$ Halina Ekiert

halina.ekiert@uj.edu.pl

1 Department of Pharmaceutical Botany, Collegium Medicum, Jagiellonian University, ul. Medyczna 9, 30-688 Kraków, Poland

2 Department of Medicinal Chemistry, Faculty of Pharmacy with Division of Medical Analytics, Medical University of Lublin, ul. Chodźki 4a, 20-093 Lublin, Poland 
Keywords In vitro cultures $\cdot$ Phenylalanine $\cdot$ Cinnamic acid $\cdot$ Benzoic acid $\cdot$ Caffeic acid $\cdot$ Phenolic acids

\section{Abbreviations}

$\begin{array}{ll}\text { BA } & \text { 6-Benzyladenine } \\ \text { NAA } & \text { 1-Naphthaleneacetic acid } \\ \text { MS } & \text { Murashige and Skoog } \\ \text { HPLC-DAD } & \begin{array}{l}\text { High performance liquid chromatography } \\ \text { with diode-array detector }\end{array}\end{array}$

\section{Introduction}

The pharmaceutical, cosmetics and health-food industry always look for new rich natural plant sources of antioxidants (Krishnaiah et al. 2011). This group of compounds possesses very valuable biological properties-they prevent a lot of lifestyle diseases (such as strokes, heart attacks, and neurodegenerative diseases), and can also be used as antiaging agents (Young and Woodside 2001; Matkowski 2008; Krishnaiah et al. 2011).

Aronia genus, a representative of the Rosaceae family, is a rich source of natural antioxidants (Kulling and Rawel 2008; Kokotkiewicz et al. 2010).

Aronia melanocarpa (Michx.) Elliott (black aronia) and Aronia arbutifolia (L.) Pers. (red aronia) are plant species of North American origin, cultivated in Central European countries. The fruits of black aronia are more famous than a plant raw material. They are rich in various groups of antioxidants, almost all polyphenols, e.g. phenolic acids and anthocyanins, procyanidin $\mathrm{B}_{1}$, and also in flavonoids of high antioxidant activity. The presence of caffeic acid and two depsides (chlorogenic and neochlorogenic acid) was confirmed in fruit extracts. Anthocyanins are represented by cyanidin derivatives (cyanidin-3-galactoside and cyanidin3 -arabinoside), whereas flavonoids by quercetin and its glycosides-quercitrin and rutoside. The fruits are additionally rich in vitamins- $\mathrm{C}, \mathrm{E}, \mathrm{K}$, folic acid, as well as B-group vitamins and organic acids (Zhao et al. 2004; Kokotkiewicz et al. 2010; Taheri et al. 2013; Szopa et al. 2017).

The knowledge about the chemical composition of red aronia fruits is very poor (Taheri et al. 2013). The earlier phytochemical studies performed by our team documented high amounts of various subgroups of polyphenols, chlorogenic acid, neochlorogenic acid, cyanidin glycosides, quercetin, quercitrin, and rutoside. Our studies provided additionally evidence that the leaves of both aronias are also a rich source of various polyphenols (Szopa et al. 2017).

Biotechnological studies with different types of in vitro cultures of both black and red aronias (callus and shoot cultures, and solid and agitated cultures) performed by our team documented very high biosynthetic potential of cells of the tested plants in in vitro culture conditions. They produced especially high amounts of phenolic acids. We looked for the most beneficial conditions for the production of this group of antioxidants (Szopa et al. 2013, 2018b, c, d; Szopa and Ekiert 2014).

Phenolic acids are not only strong antioxidants. They possess a lot of other valuable biological activities, such as cytotoxic, anti-inflammatory, immunostimulatory, hypolipaemic, hepatoprotective and antiaggregatory, and these properties are the main reason of our studies in this area (Cai et al. 2004; Itoh et al. 2010; Rosa et al. 2016).

So far, we tested the production of phenolic acids in in vitro cultures of both aronias under various basal media composition, concentration of plant growth regulators and light conditions (monochromatic and multispectral lights), as well as the type of culture (solid and agitated cultures) (Szopa et al. 2013; Szopa and Ekiert 2014; Szopa et al. $2018 \mathrm{c}, \mathrm{b})$. In the current part of investigation, we decided to investigate the effects of feeding culture media with biosynthetic precursors of phenolic acids.

Our earlier results allowed us to choose one optimal variant of Murashige-Skoog (MS) medium (Murashige and Skoog 1962) enriched with $1 \mathrm{mg} / \mathrm{l} \mathrm{BA}$ (6-benzyladenie) and $1 \mathrm{mg} / \mathrm{l}$ NAA (1-naphthaleneacetic acid) as a good universal "productive medium" for in vitro cultures of both aronias (Szopa et al. 2013, 2018d; Szopa and Ekiert 2014).

This paper presents the effect of addition of biosynthetic precursors of phenolic acids-phenylalanine, cinnamic acid and benzoic acid to the cultures media on production of phenolic acids. Additionally, the effect of supplementation of culture media with a biosynthetic precursor of depsides (caffeic acid) was studied. The work assumed wide range of the experiments-each of precursors was administered at 5 different concentrations in the range $0.1-10.0 \mathrm{mmol} / \mathrm{l}$ at 2 different points in time. The study allowes to expand the theoretical knowledge about plant in vitro cultures precursor feeding, and gives the potentially applicative results.

\section{Materials and methods}

\section{In vitro cultures establishment}

The establishment of shoot in vitro cultures of Aronia melanocarpa (Michx.) Elliott and Aronia arbutifolia (L.) Pers. was described previously (Szopa et al. 2018b, c, d). The cultures were maintained on the MS medium (Murashige and Skoog 1962) with addition of $1 \mathrm{mg} / \mathrm{l} \mathrm{BA}$ (6-benzyladenine) and $1 \mathrm{mg} / \mathrm{l}$ NAA (1-naphthaleneacetic acid), 3\% sucrose $(\mathrm{w} / \mathrm{v}), \mathrm{pH}=5.7$. This medium was chosen in earlier research as the best medium for biomass growth and accumulation of 
bioactive compounds (Szopa et al. 2018d, c, b). The cultures were grown in plant tissue vessels $(100 \mathrm{ml}, 66 \mathrm{~mm} \times 59 \mathrm{~mm})$ with special Magenta B-caps (Sigma-Aldrich, St. Louis, $\mathrm{MO}$, USA), in a phytotron in temperature $25 \pm 2^{\circ} \mathrm{C}$ under constant LED light $\left(2.75 \mathrm{~W} / \mathrm{m}^{2}\right)$, being transferred onto the same fresh medium every 4 weeks.

\section{Experimental in vitro cultures}

The experimental shoot cultures of A. melanocarpa and A. arbutifolia (Figs. S1-S8) were maintained in $300 \mathrm{ml}$ Erlenmeyer flasks in liquid MS medium with various concentrations of 4 precursors: phenylalanine, cinnamic acid, benzoic acid and caffeic acid (Sigma-Aldrich, St. Louis, MO, USA). Each of them was tested in $0.1,0.5,1,5,10 \mathrm{mmol} / \mathrm{l}$. The inoculum consisted of $1.5 \mathrm{~g}$ of fresh shoots per one flask. The precursors were added to the culture media at two time points: in the beginning of the growth cycle (point " 0 ") and after 10 days. The precursors were added using $0.1 \mathrm{mmol} / \mathrm{ml}$ stock solutions prepared in the following manner: the phenylalanine was dissolved in gently heated deionized water, whereas benzoic, caffeic and cinnamic acids were dissolved in minimal amount of $1 \mathrm{~mol} / \mathrm{l}$ natrium hydroxide followed by dilution with deionized water, obtaining $0.1 \mathrm{mmol} / \mathrm{ml}$ precursor concentration. Stock solutions were filtered using syringe filters $(0.2 \mu \mathrm{m})$ under laminar flow hood. The final concentrations of each precursors were obtained by adding of $90 \mathrm{ml}$ of the MS experimental media to $10 \mathrm{ml}$ of aqueous solution of a precursor. The following concentrations of precursors were reached: $90 \mathrm{ml} \mathrm{MS}$ medium $+0.1 \mathrm{ml}$ precursor stock solution $+9.9 \mathrm{ml}$ sterile redistilled water $=0.1 \mathrm{mmol} / 1$ concentration of precursor; $90 \mathrm{ml}$ MS medium $+0.5 \mathrm{ml}$ precursor stock solution $+9.5 \mathrm{ml}$ sterile redistilled water $=0.5 \mathrm{mmol} / \mathrm{l}$ concentration of precursor; $90 \mathrm{ml} \mathrm{MS}$ medium $+1 \mathrm{ml}$ precursor stock solution $+9 \mathrm{ml}$ sterile redistilled water $=1 \mathrm{mmol} / \mathrm{l}$ concentration of precursor; $90 \mathrm{ml} \mathrm{MS}$ medium $+5 \mathrm{ml}$ precursor stock solution $+5 \mathrm{ml}$ sterile redistilled water $=5 \mathrm{mmol} / \mathrm{l}$ concentration of precursor; $90 \mathrm{ml}$ MS medium $+10 \mathrm{ml}$ precursor stock solution $=10 \mathrm{mmol} / \mathrm{l}$ concentration of precursor. For control cultures, the $100 \mathrm{ml}$ of sterile deionized water was added at the same two time points (at the beginning of the growth cycles (point " 0 ") and on the 10th day), as for experimental cultures.

The control and experimental shoot cultures were cultured under 20 days growth cycles ( 3 series) on a rotary shaker (Altel, Cracow, Poland) at $140 \mathrm{rpm}$, with a vibration amplitude of $35 \mathrm{~mm}$, in the same physical culture conditions as described above. The cultures were maintained in 3 series for each precursor, whereas 10 flasks were used for control cultures.

\section{Phenolic acid chromatographic analysis}

Methanolic extracts were prepared with $0.5 \mathrm{~g}$ lyophilized (Labconco lyophilizer, Kansas City, MO, USA) and pulverized biomass from in vitro cultures. The material was extracted for $2 \mathrm{~h}$ with methanol $(50 \mathrm{ml})$ under reflux condenser. The obtained extracts were filtered through filter paper (Whatman ${ }^{\mathrm{TM}}$ ), then evaporated in a room temperature inside crystallizers. The residue was dissolved in $2 \mathrm{ml}$ of HPLC-grade methanol (Merck KGaA, Darmstadt, Germany) and filtered with sterilizing syringe filters $(0.22 \mu \mathrm{m}$, Millex ${ }^{\circledR}$ GP, Millipore, Sigma-Aldrich, St. Louis, MO, USA) prior to HPLC analysis.

The analysis of phenolic acids was performed by the HPLC-DAD method (Ellnain-Wojtaszek and Zgorka 1999; Sułkowska-Ziaja et al. 2017; Szopa et al. 2017). The Merck-Hitachi (Merck KGaA, Darmstadt, Germany) aparathus was used: autosampler L 2200, pump L 2130, column oven L 2350, diode array detector (DAD) L 2455 at UV range $200-400 \mathrm{~nm}$. Detection wavelength was set at $254 \mathrm{~nm}$. Analysis was carried out on Purospher RP-18e analytical column $(4 \times 250 \mathrm{~nm}, 5 \mathrm{ml}$; Merck KGaA, Darmstadt, Germany). The mobile phase consisted of: A-methanol: 0.5\% acetic acid $(1: 4 \mathrm{v} / \mathrm{v}) ; \mathrm{B}-$ methanol. The gradient program was as follows: $0-20 \mathrm{~min}, 0 \% \mathrm{~B}, 20-35 \mathrm{~min}, 0-20 \% \mathrm{~B}$, 35-45 min, 20-30\% B, 45-55 min, 30-40\% B, 55-60 min, 40-50\% B, 60-65 min, 50-75\% B and 65-70 $\mathrm{min}, 75-100 \%$ $\mathrm{B}$, with a hold time of $15 \mathrm{~min}$, at $25^{\circ} \mathrm{C}$. The flow rate was $1 \mathrm{ml} / \mathrm{min}$, with $10 \mu \mathrm{l}$ injection volume. Qualitative and quantitative analysis was carried out using analytical standards of the following phenolic acids: caffeic, caftaric, chlorogenic, m-coumaric, o-coumaric, p-coumaric, cryptochlorogenic, 3,4-dihydroxyphenylacetic, ellagic, ferulic, gallic, gentisic, hydrocaffeic, p-hydroxybenzoic, isochlorogenic, isoferulic, neochlorogenic, phenylacetic, protocatechuic, rosmarinic, salicylic, sinapic, syringic, vanillic acids as well as benzoic and cinnamic acids (all compounds purchased from SigmaAldrich, St. Louis, MO, USA).

\section{Statistical analysis}

The results are expressed as the mean \pm standard deviation (SD) of three independent series $(\mathrm{n}=10)$ and measurements. 'Microsoft Excel' and 'Statistica 12 PL StatSoft' were used for basic analysis. Multi-way ANOVA and post-hoc comparison was done inside $\mathrm{R}$ environment (version 3.6.3) using built-in 'Anova' and 'TukeyHSD' functions. 
Table 1 The dry biomass increments of shoots of Aronia melanocarpa and Aronia arbutifolia cultured in vitro on media supplemented with precursors at two points of growth cycles (point " 0 " and 10 th day), and in the control cultures, after 20th days growth cycles $(\mathrm{n}=10, p<0.05)$

\begin{tabular}{|c|c|c|c|c|}
\hline \multirow{2}{*}{$\begin{array}{l}\text { Precursor } \\
{[\mathrm{mmol} / \mathrm{l}]}\end{array}$} & \multicolumn{2}{|c|}{ Aronia melanocarpa } & \multicolumn{2}{|c|}{ Aronia arbutifolia } \\
\hline & Point " 0 " & 10th day & Point “0” & 10th day \\
\hline Control & $7.99 \pm 1.82$ & & $8.05 \pm 0.26$ & \\
\hline \multicolumn{5}{|c|}{ Phenylalanine } \\
\hline 0.1 & $8.84 \pm 0.95$ & $9.14 \pm 0.44$ & $9.46 \pm 0.18$ & $9.29 \pm 0.23$ \\
\hline 0.5 & $9.04 \pm 0.07$ & $9.16 \pm 0.19$ & $8.21 \pm 0.85$ & $8.79 \pm 0.63$ \\
\hline 1 & $9.04 \pm 0.13$ & $8.44 \pm 0.03$ & $8.99 \pm 0.88$ & $9.35 \pm 0.13$ \\
\hline 5 & $5.60 \pm 0.02$ & $8.49 \pm 1.92$ & $7.98 \pm 1.04$ & $8.90 \pm 1.62$ \\
\hline 10 & $2.38 \pm 0.56$ & $6.76 \pm 0.57$ & $5.35 \pm 0.03$ & $7.35 \pm 0.47$ \\
\hline \multicolumn{5}{|c|}{ Cinnamic acid } \\
\hline 0.1 & $8.36 \pm 1.01$ & $7.66 \pm 1.15$ & $8.68 \pm 0.52$ & $8.90 \pm 0.38$ \\
\hline 0.5 & $8.53 \pm 0.55$ & $7.34 \pm 1.05$ & $9.05 \pm 0.51$ & $8.36 \pm 0.79$ \\
\hline 1 & $7.71 \pm 0.68$ & $8.38 \pm 1.75$ & $8.23 \pm 2.13$ & $8.91 \pm 0.26$ \\
\hline 5 & $1.00 \pm 0.30$ & $8.41 \pm 0.59$ & $1.47 \pm 0.33$ & $8.42 \pm 0.19$ \\
\hline 10 & $0.96 \pm 0.21$ & $3.71 \pm 0.68$ & $1.29 \pm 0.06$ & $4.96 \pm 0.76$ \\
\hline \multicolumn{5}{|c|}{ Benzoic acid } \\
\hline 0.1 & $8.73 \pm 0.32$ & $8.32 \pm 1.48$ & $8.68 \pm 0.73$ & $9.26 \pm 0.03$ \\
\hline 0.5 & $9.23 \pm 0.24$ & $8.69 \pm 0.12$ & $9.13 \pm 0.08$ & $8.88 \pm 0.10$ \\
\hline 1 & $7.28 \pm 1.00$ & $8.71 \pm 0.09$ & $8.43 \pm 1.43$ & $8.23 \pm 0.08$ \\
\hline 5 & $1.31 \pm 0.37$ & $9.59 \pm 0.11$ & $5.49 \pm 0.33$ & $8.59 \pm 0.08$ \\
\hline 10 & $1.17 \pm 0.04$ & $7.19 \pm 3.07$ & $2.03 \pm 0.23$ & $8.21 \pm 0.25$ \\
\hline \multicolumn{5}{|c|}{ Caffeic acid } \\
\hline 0.1 & $9.14 \pm 0.27$ & $7.96 \pm 0.23$ & $8.01 \pm 0.59$ & $7.82 \pm 0.48$ \\
\hline 0.5 & $8.79 \pm 0.90$ & $6.46 \pm 0.03$ & $7.54 \pm 0.42$ & $8.77 \pm 0.60$ \\
\hline 1 & $8.33 \pm 0.38$ & $7.65 \pm 0.62$ & $8.43 \pm 0.10$ & $7.60 \pm 0.24$ \\
\hline 5 & $6.60 \pm 0.16$ & $7.74 \pm 0.74$ & $7.38 \pm 0.52$ & $8.40 \pm 0.69$ \\
\hline 10 & $3.89 \pm 1.12$ & $8.30 \pm 1.47$ & $5.63 \pm 0.08$ & $8.27 \pm 0.19$ \\
\hline
\end{tabular}

\section{Results}

\section{Aronia melanocarpa (black aronia) shoot cultures}

\section{Control cultures}

After 20-days of Aronia melanocarpa control culture growth, 8.0-fold increase in dry biomass was confirmed (Table 1, Figs. S1-S4). Among 24 phenolic acids suspected in the methanolic extracts from the biomass of shoots, 7 phenolic acids were detected-5 depsides: neochlorogenic, chlorogenic, cryptochlorogenic, isochlorogenic and rosmarinic acids, as well as caffeic and syringic acids (Table 2). The main metabolites were: isochlorogenic acid (104.54 mg/100 g DW), chlorogenic acid (82.53 mg/100 g DW) and neochlorogenic acid (73.69 mg/100 g DW). The amounts of the other compounds were considerably smaller; they ranged from 4.26 to $14.30 \mathrm{mg} / 100 \mathrm{~g} \mathrm{DW}$. The total amount of these 7 metabolites reached $290.10 \mathrm{mg} / 100 \mathrm{~g} \mathrm{DW}$ (Table 2).

\section{Experimental cultures}

In the experimental cultures (especially in these with precursor added at point " 0 " in higher concentrations -5 and $10 \mathrm{mmol} / \mathrm{l})$, the decrease in obtained biomass was observed. The presence of the same metabolites was confirmed-five depsides (neochlorogenic, chlorogenic, cryptochlorogenic, isochlorogenic and rosmarinic acids) and two phenolic acids - caffeic and syringic acids. The detected compounds were exactly the same as in control cultures. The addition of precursors had no influence on the presence (or impresence) of accumulated metabolites, but it influenced the quantity of individual compounds and consequently their total amounts. The main metabolites in all studied extracts were three depsides: neochlorogenic, chlorogenic and isochlorogenic acids.

\section{Effects of feeding with phenylalanine}

\section{Biomass increments}

The increase of the dry biomass in the experimental cultures supplemented with lower concentrations of phenylalanine (0.1-1.0 mmol/l) was high (8.4-9.2-fold) and higher than that in control cultures. The decrease in the biomass increments was observed with the highest addition of phenylalanine (5 and $10 \mathrm{mmol} / \mathrm{l})$, especially after addition of the precursor at point " 0 " (5.6-fold increase by $5 \mathrm{mmol} / \mathrm{l}$ and only 2.4 -fold increase by $10 \mathrm{mmol} / \mathrm{l}$ ) (Table 1 , Fig. S1).

\section{Accumulation of metabolites}

\section{Point " 0 "-1st day of growth cycles}

The main compounds detected in the analyzed extracts were 3 depsides: neochlorogenic, chlorogenic and isochlorogenic acids (Table 2 ). Their amounts varied considerably (3.6-, 4.3- and 3.4-fold), depending on the concentration of the precursor: $28.94(10 \mathrm{mmol} / \mathrm{l})-103.84 \mathrm{mg} / 100 \mathrm{~g} \mathrm{DW}$ (1 mmol/l), 38.54 (10 mmol/l) - $165.74 \mathrm{mg} / 100 \mathrm{~g} \mathrm{DW}$ (5 mmol/l) and $38.44(10 \mathrm{mmol} / \mathrm{l})-129.06 \mathrm{mg} / 100 \mathrm{~g} \mathrm{DW}$ (1 mmol/l), respectively. Three other compounds were accumulated in quantities of a another order of magnitude: syringic acid (max. $36.00 \mathrm{mg} / 100 \mathrm{~g} \mathrm{DW}$ ), rosmarinic acid (max. $19.66 \mathrm{mg} / 100 \mathrm{~g} \mathrm{DW}$ ) and caffeic acid (max. $16.24 \mathrm{mg} / 100 \mathrm{~g}$ DW). Only the amounts of cryptochlorogenic acid were greater, 24.69-62.53 mg/100 g DW (Table 2).

The total amounts of the seven metabolites varied within wide limits, from 196.52 (10 mmol/l) to 481.07 (5 mmol/l), depending on the concentration of phenylalanine. The 


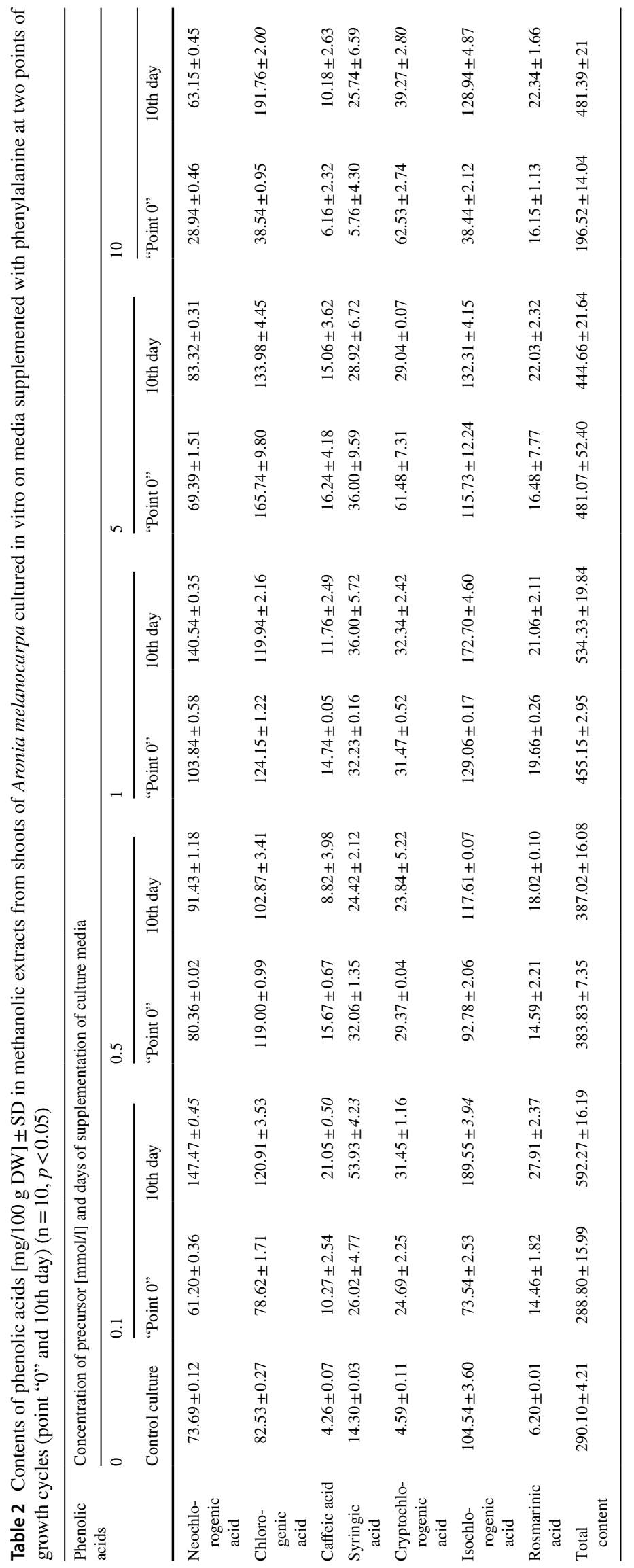


highest total amount was 1.7-fold higher than that of control culture (Table 2).

\section{0th day of growth cycles}

The main detected metabolites in extracts were the same 3 depsides-isochlorogenic, chlorogenic and neochlorogenic acids (Table 2). The amounts of them varied depending on the precursor concentration (1.6, 1.9 and 2.3-fold), in the following ranges: $117.61(0.5 \mathrm{mmol} / \mathrm{l})-189.55$ $(0.1 \mathrm{mmol} / \mathrm{l}), 102.87(0.5 \mathrm{mmol} / \mathrm{l})-191.76(10 \mathrm{mmol} / \mathrm{l})$ and $63.15(10 \mathrm{mmol} / \mathrm{l})-147.47 \mathrm{mg} / 100 \mathrm{~g}$ DW (0.1 mmol/l), respectively. The confirmed amounts of cryptochlorogenic acid were considerably lower, 23.84 $(0.5 \mathrm{mmol} / \mathrm{l})-39.27 \mathrm{mg} / 100 \mathrm{~g} \mathrm{DW}(10 \mathrm{mmol} / \mathrm{l})$. The amount of another depside-rosmarinic acid-was also significantly lower, ranging from 18.02 to $27.91 \mathrm{mg} / 100 \mathrm{~g}$ DW. Syringic acid was accumulated in the shoots in slightly larger amounts, $24.42-53.93 \mathrm{mg} / 100 \mathrm{~g}$ DW. The smallest accumulated amounts were those of caffeic acid, with the confirmed max. value of $21.05 \mathrm{mg} / 100 \mathrm{~g}$ DW (Table 2). The total amounts of the 7 metabolites changed 1.5-fold from $387.02(0.5 \mathrm{mmol} / \mathrm{l})$ to $592.27 \mathrm{mg} / 100 \mathrm{~g} \mathrm{DW}(0.1 \mathrm{mmol} / \mathrm{l})$. The highest total amount was about two-fold higher than that of control culture and 1.2 fold higher than the highest amounts confirmed after administration of phenylalanine at point "0" (Table 2).

\section{Effects of feeding with cinnamic acid}

\section{Biomass increments}

The supplementation of the culture media with cinnamic acid in concentrations $0.1-1.0 \mathrm{mmol} / \mathrm{l}$ was beneficial for the dry biomass increments during 20 days; 7.3-8.5-fold increases were observed. On the other hand, the addition of this precursor in concentration 5 and $10 \mathrm{mmol} / \mathrm{l}$ at point " 0 " totally stopped the growth of the shoots. By addition of this precursor at 10 day of the growth cycles in $10 \mathrm{mmol} / \mathrm{l}$, only 3.7-fold increase was confirmed (Table 1, Fig. S2).

\section{Accumulation of metabolites}

\section{Point " 0 "-1st day of growth cycles}

The main metabolites in the extracts were also 3 depsidesisochlorogenic acid, chlorogenic acid and neochlorogenic acid (Table 3). The amounts of these compounds were high, they varied: 5.2, 20.1 and 3.1-fold depending on the concentration of cinnamic acid, from $30.36(10 \mathrm{mmol} / \mathrm{l})$ to $158.39 \mathrm{mg} / 100 \mathrm{~g} \mathrm{DW}(5 \mathrm{mmol} / \mathrm{l})$, from $8.45(10 \mathrm{mmol} / \mathrm{l})$ to $169.76 \mathrm{mg} / 100 \mathrm{~g} \mathrm{DW}(0.5 \mathrm{mmol} / \mathrm{l})$, and from 36.40

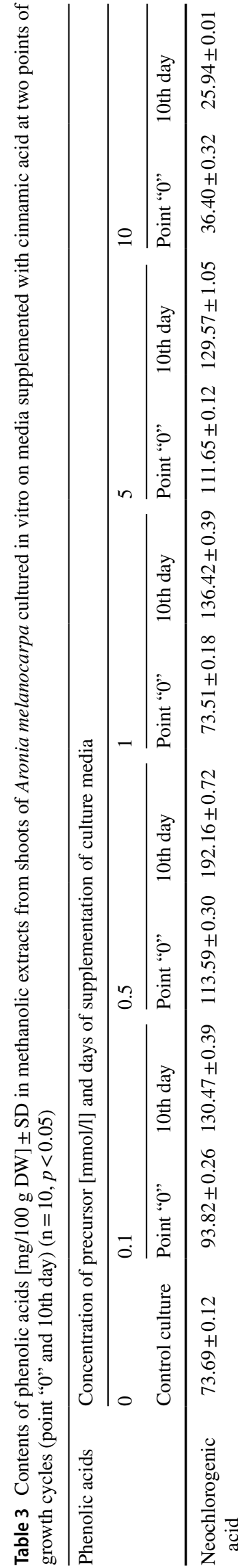

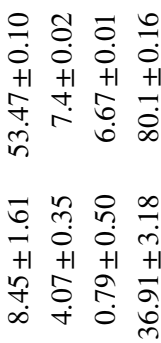

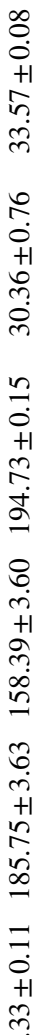

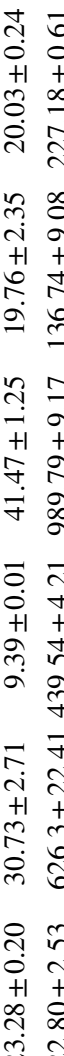

$\exists \stackrel{\infty}{*}$ के

$+1+1+1$

थี 7 bे

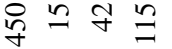

গิ

$+1+1+1$

¿

ก 2 it

$\begin{array}{llll}+1 & \dot{m} & \dot{0} & \dot{+} \\ +1 & +1 & +1\end{array}$

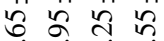

$\infty$ I

๓ ๖ำ ๆ

$\begin{array}{llll}0 & 0 & 0 & - \\ +1 & +1 & +1 & +1\end{array}$

$\because$ m

in ते ते

m $\infty$ ก

$\dot{+}+1+1$

ले 200

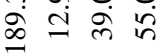

ล

$\begin{array}{llll}\dot{0} & \dot{0} & \dot{0} & \dot{0} \\ +1 & +1 & +1 & +1\end{array}$

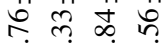

gิ

ปิ

$\begin{array}{llll}0 & 0 & 0 & 0 \\ +1 & +1 & +1 & +1\end{array}$

放士 n

ป

$\stackrel{\infty}{\sim}$ กิ กิ

0 000

0 4

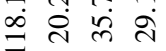

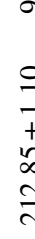

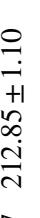

$m$ ㅇ

ஸे ஸे

$+1+1$

d

ले ले

잉 우

$\stackrel{+1}{+}+$

in

ลิ ซี

m $q$

+

\&

กั

ष 6

i

工

ते

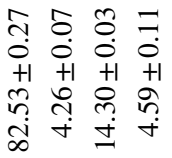

8
8
$\dot{m}$
+1
+
$\dot{0}$
0

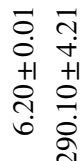
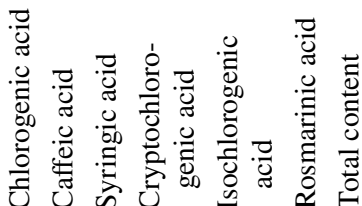
(10 mmol/l) to $113.59 \mathrm{mg} / 100 \mathrm{~g} \mathrm{DW}(0.5 \mathrm{mmol} / \mathrm{l})$, respectively. The remaining four compounds-two depsides: cryptochlorogenic and rosmarinic acid, and syringic and caffeic acids-were accumulated in much smaller amounts. The amounts of these two depsides reached maximally $36.91 \mathrm{mg} / 100 \mathrm{~g}$ DW and $27.55 \mathrm{mg} / 100 \mathrm{~g} \mathrm{DW}$, respectively. The largest amounts of syringic acid reached $35.84 \mathrm{mg} / 100 \mathrm{~g}$ DW, and for caffeic acid $20.22 \mathrm{mg} / 100 \mathrm{~g} \mathrm{DW}$ (Table 3).

The total amounts of the 7 compounds ranged about four-fold from $136.74 \mathrm{mg} / 100 \mathrm{~g}$ DW $(10 \mathrm{mmol} / \mathrm{l})$ to $543.37 \mathrm{mg} / 100 \mathrm{~g}$ DW $(0.5 \mathrm{mmol} / \mathrm{l})$. The reached maximal total content was 1.9-fold higher than in control culture (Table 3).

\section{0th day of growth cycles}

The compounds accumulated in the shoot extracts in largest amounts were also 3 depsides-isochlorogenic, chlorogenic and neochlorogenic acids (Table 3). The lowest isochlorogenic acid content $(33.57 \mathrm{mg} / 100 \mathrm{~g} \mathrm{DW})$ was found at the highest tested concentration of the precursor- $10 \mathrm{mmol} / \mathrm{l}$. The maximum amount of this compound $(212.85 \mathrm{mg} / 100 \mathrm{~g}$ DW) was proven for cinnamic acid in concentration of $0.5 \mathrm{mmol} / \mathrm{l}$. The amounts of the other two aforementioned depsides were in ranges $53.47-450.35 \mathrm{mg} / 100 \mathrm{~g}$ DW and 25.94-192.16 mg/100 g DW, respectively. The lowest amount of these compounds was confirmed also in concentration of the precursor equal to $10 \mathrm{mmol} / \mathrm{l}$, and the highest also in $0.5 \mathrm{mmol} / \mathrm{l}$. Cryptochlorogenic and rosmarinic acid were accumulated in significant lower amounts, from 31.55 to $115.56 \mathrm{mg} / 100 \mathrm{~g}$ DW and from 20.03 to $41.47 \mathrm{mg} / 100 \mathrm{~g}$ DW, respectively. The obtained maximum amounts of the two remaining phenolic acids - syringic and caffeic acids did not exceed $40 \mathrm{mg} / 100 \mathrm{~g} \mathrm{DW}$ (Table 3 ).

The total amounts varied widely, from $227.18(10 \mathrm{mmol} / \mathrm{l})$ up to $989.79 \mathrm{mg} / 100 \mathrm{~g} \mathrm{DW}(5 \mathrm{mmol} / \mathrm{l})$. The maximal value was 3.4-fold higher than that of the control culture and 1.8fold higher than the max. value after addition of cinnamic acid at point " 0 " (Table 3 ).

\section{Effects of feeding with benzoic acid}

\section{Biomass increments}

The addition of benzoic acid in $0.1-5 \mathrm{mmol} / \mathrm{l}$ concentration into the culture media on 10th day was beneficial for the dry biomass increments; 8.3-9.6-fold increases were documented and they were higher than in the control culture. The same effect was observed after addition of this precursor at point " 0 ", but only in low concentrations $(0.1 \mathrm{mmol} / \mathrm{l}$ and $1.0 \mathrm{mmol} / 1,8.7$ and 9.2-fold increase was confirmed). The highest concentrations of precursor ( 5 and $10 \mathrm{mmol} / \mathrm{l}$ ) supplemented into the media at point " 0 " almost stopped

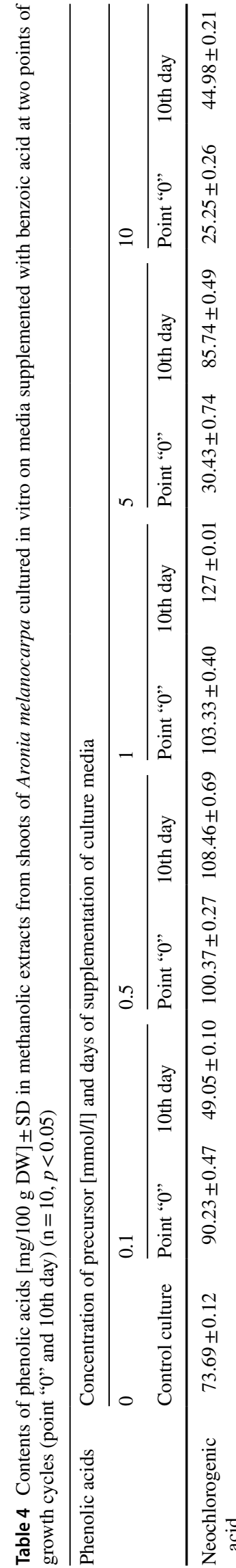

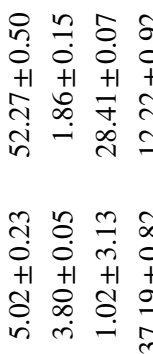

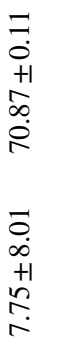

$\stackrel{\sim}{\top} \infty \infty \infty$

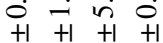

$\simeq m \cong \infty$

å

으 의

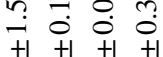

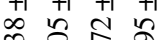

ปู 0 กิ

๙ ते के

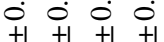

$\infty \underset{0}{\infty} 0 \infty$

○் मேं

$\infty \approx m$ ๖

$\begin{array}{llll}+1 & +1 & 0 & + \\ 0 & +1\end{array}$

$\infty \sqrt{6}$ \&

宁

च ஃ

$7+{ }_{+1}+1$

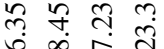

- $\infty$ ते

ต어

$\begin{array}{cccc}0 & - & 0 & n \\ 0 & 0 & 0 \\ +1 & +1 & +1 & +1 \\ +1 & +1 & 0 & 0\end{array}$

$6 \infty$ b

๙

๖

$\begin{array}{lll}0 & +1 & +1 \\ +1 & +1\end{array}$

ปㅊำ

$\stackrel{\infty}{\infty} \infty$

สู กี ั

$\begin{array}{llll}i & 0 & 0 & \dot{0} \\ +1 & +1 & +1 & +1\end{array}$

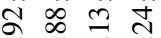

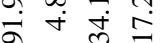

प 8

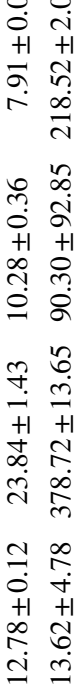

+1

त

$n$
$\infty$
a
+1

$\begin{array}{ll}+1 & +1 \\ 0 & 0\end{array}$

\% ?

त்

$\simeq \infty$ 
the biomass increase. Very small (1.3- and 1.2-fold, respectively) increments were documented (Table 1, Fig. S3).

\section{Accumulation of metabolites}

\section{Point " 0 " -1 st day of growth cycles}

The main compounds detected in methanolic extracts were the aforementioned depsides, which also had a dominant quantities in the control cultures-isochlorogenic, chlorogenic and neochlorogenic acids (Table 4). The amounts of isochlorogenic acid varied 18.2-fold depending on the precursor concentration, from $7.75(10 \mathrm{mmol} / \mathrm{l})$ to $140.90 \mathrm{mg} / 100 \mathrm{~g} \mathrm{DW}(0.5 \mathrm{mmol} / \mathrm{l})$. Similarly, the amounts of chlorogenic and neochlorogenic acid varied widely, 22.0and 4.1-fold, from $5.02(10 \mathrm{mmol} / \mathrm{l})$ to $110.58 \mathrm{mg} / 100 \mathrm{~g} \mathrm{DW}$ $(1 \mathrm{mmol} / \mathrm{l})$, and from $25.25(10 \mathrm{mmol} / \mathrm{l})$ to $103.33 \mathrm{mg} / 100 \mathrm{~g}$ DW (1 mmol/l), respectively (Table 4).

The cryptochlorogenic acid content was very high$227.95 \mathrm{mg} / 100 \mathrm{~g}$ DW in the culture with benzoic acid added in $5 \mathrm{mmol} / \mathrm{l}$. However, all other tested concentrations of the precursor yielded with much lower amounts of this metabolite, ranging from 17.24 to $37.19 \mathrm{mg} / 100 \mathrm{~g}$ DW. Among the depsides, rosmarinic acid was accumulated in the smallest amount (max. $19.64 \mathrm{mg} / 100 \mathrm{~g} \mathrm{DW}$ ). Overall, caffeic acid was accumulated in the smallest amount (max. $9.65 \mathrm{mg} / 100 \mathrm{~g} \mathrm{DW}$ ). The amount of syringic acid varied within very wide limits, from 0.72 to $47.46 \mathrm{mg} / 100 \mathrm{~g}$ DW (Table 4).

The total amount of analyzed 7 compounds varied considerably (4.9-fold), from 90.3 (10 mmol/l) to $439.44 \mathrm{mg} / 100 \mathrm{~g}$ DW $(1 \mathrm{mmol} / \mathrm{l})$. The maximal value was 1.5 -fold higher than in control culture (Table 4).

\section{0th day of growth cycles}

The quantitatively dominant compounds in analyzed extracts of the shoots were also the same 3 depsides-isochlorogenic, chlorogenic and neochlorogenic acids whose presence was confirmed at point " 0 " (Table 4). These compounds were accumulated in varying amounts and differed 2.4-, 3.3- and 2.8-fold, depending on the concentration of the precursor, from 70.87 to $168.23 \mathrm{mg} / 100 \mathrm{~g} \mathrm{DW}$, from 52.27 to $119.08 \mathrm{mg} / 100 \mathrm{~g} \mathrm{DW}$, and from 44.98 to $127.00 \mathrm{mg} / 100 \mathrm{~g}$ DW, respectively. For these 3 compounds, their minimal amounts were confirmed at the highest precursor concentration tested $(10 \mathrm{mmol} / \mathrm{l})$. In turn, their maximal amounts were proven for precursor concentration equal to $1 \mathrm{mmol} / \mathrm{l}$. At the lowest precursor concentration $(0.1 \mathrm{mmol} / \mathrm{l})$, a very high amount of cryptochlorogenic acid $(157.42 \mathrm{mg} / 100 \mathrm{~g}$ DW) was found. At higher concentrations, the amount of this metabolite was several times lower (max. $24.38 \mathrm{mg} / 100 \mathrm{~g}$ DW). The amounts of rosmarinic acid less varied, from
7.91 to $23.89 \mathrm{mg} / 100 \mathrm{~g}$ DW. Syringic acid was accumulated in similar amounts, regardless of benzoic acid concentration (18.96-37.23 mg/100 g DW). The metabolite accumulated in the smallest quantities was caffeic acid (1.86-10.71 mg/100 g DW) (Table 4).

The total amounts of the 7 phenolic acids increased more than 2.3 -fold, from $218.52 \mathrm{mg} / 100 \mathrm{~g} \mathrm{DW}$ (at $10 \mathrm{mmol} / \mathrm{l}$ ) to $503.02 \mathrm{mg} / 100 \mathrm{~g} \mathrm{DW}$ (at $1 \mathrm{mmol} / \mathrm{l}$ ). The highest total value were 1.7-fold higher than that of control culture and 1.1-fold higher than the highest value estimated after supplementation of media with benzoic acid at point " 0 " (Table 4).

\section{Effect of feeding with caffeic acid}

\section{Biomass increments}

The addition of caffeic acid into the culture media at point " 0 " in concentrations in the range $0.1-5.0 \mathrm{mmol} / \mathrm{l}$ and at 10 th day of growth cycles in all concentrations $(0.1-10 \mathrm{mmol} / \mathrm{l})$ influenced positively the dry biomass increments (6.6-9.2fold). Although the highest concentration $(10 \mathrm{mmol} / \mathrm{l})$ supplemented at point " 0 " resulted in negative influence of this precursor on the biomass growth (only 3.9-fold increment) (Table 1, Fig. S4).

\section{Accumulation of metabolites}

\section{Point " 0 "-1st day of growth cycles}

The quantitatively dominant metabolites were also three depsides: isochlorogenic acid, chlorogenic acid and neochlorogenic acid (Table 5). Their amounts ranged: 2.1-, 1.6-, 1.9-fold; $83.46(0.5 \mathrm{mmol} / \mathrm{l})-175.54 \mathrm{mg} / 100 \mathrm{~g} \mathrm{DW}$ (1 mmol/l), $89.83(0.5 \mathrm{mmol} / \mathrm{l})-139.07 \mathrm{mg} / 100 \mathrm{~g} \mathrm{DW}$ $(1 \mathrm{mmol} / \mathrm{l})$, and $90.28(10 \mathrm{mmol} / \mathrm{l})-167.05 \mathrm{mg} / 100 \mathrm{~g} \mathrm{DW}$ ( $1 \mathrm{mmol} / \mathrm{l})$, respectively. The cryptochlorogenic acid content was also relatively high but only when the precursor concentration was equal to $1 \mathrm{mmol} / \mathrm{l}(106.00 \mathrm{mg} / 100 \mathrm{~g} \mathrm{DW})$. In the remaining cultures, the amounts of this depside varied slightly, from 34.39 to $46.26 \mathrm{mg} / 100 \mathrm{~g}$ DW. Among the remaining 3 phenolic acids, syringic acid and rosmarinic acid were notable for being present in visibly higher amounts (max. 63.09 and max. $147.23 \mathrm{mg} / 100 \mathrm{~g} \mathrm{DW}$, respectively), comparing to caffeic acid (max. $21.58 \mathrm{mg} / 100 \mathrm{~g} \mathrm{DW}$ ) (Table 5).

The total amounts of phenolic acids obtained after feeding with caffeic acid varied 1.8-fold depending on the precursor concentration, ranging from $363.68(0.5 \mathrm{mmol} / \mathrm{l})$ to $660.62 \mathrm{mg} / 100 \mathrm{~g}$ DW $(1 \mathrm{mmol} / \mathrm{l})$. The maximal content was 2.3-fold higher than in control culture (Table 5). 


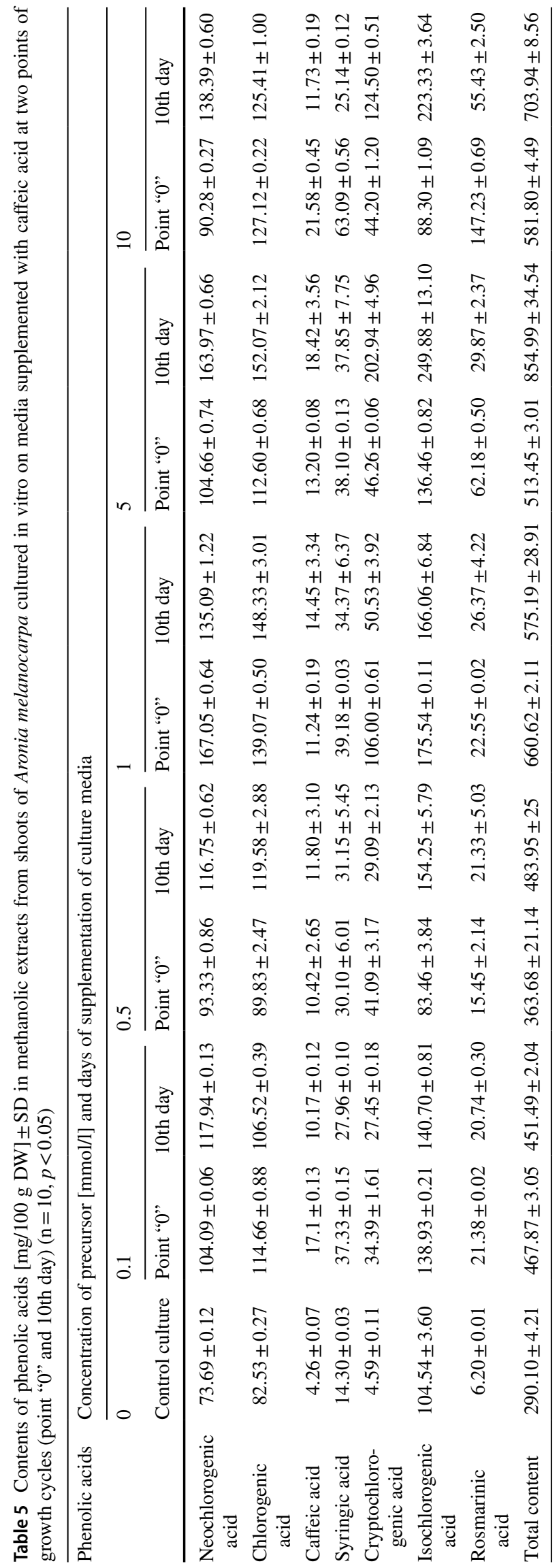


10th day of growth cycles

The main compounds in the shoot extracts were also 3 depsides (Table 5) whose amounts ranged 1.8-, 1.4- and 1.4-fold: isochlorogenic acid: $140.70(0.1 \mathrm{mmol} / \mathrm{l})-249.88 \mathrm{mg} / 100 \mathrm{~g}$ DW $(5 \mathrm{mmol} / \mathrm{l})$, chlorogenic acid: 106.52 $(0.1 \mathrm{mmol} / \mathrm{l})-152.07 \mathrm{mg} / 100 \mathrm{~g} \mathrm{DW}(5 \mathrm{mmol} / \mathrm{l})$, and neochlorogenic acid: $116.75(0.5 \mathrm{mmol} / \mathrm{l})-163.97 \mathrm{mg} / 100 \mathrm{~g}$ DW $(5 \mathrm{mmol} / \mathrm{l})$. High amounts of cryptochlorogenic acid were found in cultures supplemented with higher concentrations $-10 \mathrm{mmol} / \mathrm{l}$ and $5 \mathrm{mmol} / \mathrm{l}$ of precursor, 124.50 and $202.94 \mathrm{mg} / 100 \mathrm{~g}$ DW, respectively. In the lower concentrations, the amounts were considerably lower, ranging from 27.45 to $50.53 \mathrm{mg} / 100 \mathrm{~g}$ DW. The amounts of rosmarinic acid and syringic acid were significantly lower (Table 5): max. $55.43 \mathrm{mg} / 100 \mathrm{~g}$ DW, and max. $37.85 \mathrm{mg} / 100 \mathrm{~g}$ DW, respectively. Caffeic acid was accumulated in the smallest amounts (max. $18.42 \mathrm{mg} / 100 \mathrm{~g} \mathrm{DW}$ ) (Table 5).

The total amounts of phenolic acids varied 1.9-fold depending on the concentration of caffeic acid added, from $451.49(0.1 \mathrm{mmol} / \mathrm{l})$ to a maximum value of $854.99 \mathrm{mg} / 100 \mathrm{~g}$ DW $(10 \mathrm{mmol} / \mathrm{l})$. The highest total content was 2.9 -fold higher than in control culture and 1.9-fold higher than the highest content confirmed after addition of caffeic acid into the media at point " 0 " (Table 5).

To sum up, the maximal total amounts of estimated metabolites were obtained after addition of cinnamic acid and caffeic acid at concentration of $5 \mathrm{mmol} / \mathrm{l}$ on 10th day of A. melanocarpa culture growth (about 0.99 and $0.85 \mathrm{~g} / 100 \mathrm{~g}$ DW). They were 3.4- and 2.9-fold higher than in the cultures maintained without the precursors supplementation (control). Enough satisfied results were obtained also after supplementation of a culture media with phenylalanine $(0.1 \mathrm{mmol} / \mathrm{l}$ at 10th day) and benzoic acid $(1 \mathrm{mmol} / \mathrm{l}$ at 10 th day) -0.59 and $0.50 \mathrm{~g} / 100 \mathrm{~g}$ DW of total phenolic acids, respectively. They were 2.0 - and 1.7 -fold higher in comparison with control, respectively.

\section{Aronia arbutifolia (red aronia) shoot cultures}

\section{Control cultures}

In the control culture of Aronia arbutifolia after 20-days growth cycles 8.1 -fold dry biomass increments were documented (Table 1, Figs. S5-S8).

The methanolic extracts of the shoots were proven to contain 7 out of the 24 analyzed phenolic acids; they included 5 depsides-neochlorogenic, chlorogenic, cryptochlorogenic, isochlorogenic and rosmarinic acid, and syringic and caffeic acids (Table 6). They were the same compounds whose presence was confirmed in the extracts from A. melanocarpa shoots. The amounts of two depsides-chlorogenic acid $(66.47 \mathrm{mg} / 100 \mathrm{~g} \mathrm{DW})$ and isochlorogenic acid
$(58.83 \mathrm{mg} / 100 \mathrm{~g} \mathrm{DW})$-were notably higher than those of the other compounds. Cryptochlorogenic and syringic acid were accumulated in much smaller amounts (about $20 \mathrm{mg} / 100 \mathrm{~g}$ DW). The remaining 3 compounds (neochlorogenic, rosmarinic and caffeic acids) were accumulated in even smaller amounts (3.75-11.72 mg/100 g DW). The total amounts of all the metabolites reached $193.74 \mathrm{mg} / 100 \mathrm{~g}$ DW (Table 6).

\section{Experimental cultures}

The highest decreases of biomass increments in the experimental cultures of A. arbutifolia was observed for the highest concentrations of precursors $(10 \mathrm{mmol} / \mathrm{l})$ added into the media at "point 0 ". Especially the highest concentrations of cinnamic acid (5 and $10 \mathrm{mmol} / \mathrm{l})$ and benzoic acid (10 $\mathrm{mmol} / \mathrm{l})$ stopped the biomass growth. The presence of particular metabolites did not differ between four tested precursors and the control culture. It was also the same as in $A$. melanocarpa experimental cultures. The main metabolites were 2 depsides: chlorogenic and isochlorogenic acid. Additionally cryptochlorogenic acid was accumulated in considerable amounts. In the experimental culture of this species neochlorogenic acid was accumulated at lower amounts in comparison with in vitro culture of $A$. melanocarpa.

\section{Effects of feeding with phenylalanine}

\section{Biomass increments}

The dry biomass increments of cultures with phenylalanine supplementation in the range $0.1-1.0 \mathrm{mmol} / 1$ at point " 0 " and in the range $0.1-5 \mathrm{mmol} / \mathrm{l}$ at 10 th day, were higher than in the control culture (8.2-9.5-fold). Only the highest concentration $(10 \mathrm{mmol} / \mathrm{l})$ was less beneficial for the biomass growth (5.4- and 7.4-fold increments) (Table 1, Fig. S5).

\section{Accumulation of metabolites}

\section{Point " 0 " -1 st day of growth cycles}

Similar to the control culture, 2 depsides-chlorogenic acid and isochlorogenic acid, were dominant in the shoot extracts (Table 6). However, the amounts of these compounds were visibly higher than in the control culture. They varied, 2.3and 2.8-fold depending on the precursor concentration, from $73.71(10 \mathrm{mmol} / \mathrm{l})$ to $169.6 \mathrm{mg} / 100 \mathrm{~g} \mathrm{DW}(5 \mathrm{mmol} / \mathrm{l})$, and from $62.25(10 \mathrm{mmol} / \mathrm{l})$ to $147.8 \mathrm{mg} / 100 \mathrm{~g} \mathrm{DW}$ $(1 \mathrm{mmol} / \mathrm{l})$, respectively. Also the amounts of cryptochlorogenic acid were notable, ranging from $50.51(10 \mathrm{mmol} / \mathrm{l})$ to $83.91 \mathrm{mg} / 100 \mathrm{~g}$ DW $(5 \mathrm{mmol} / \mathrm{l})$. Neochlorogenic and syringic acids were accumulated in smaller quantities: max. $34.36 \mathrm{mg} / 100 \mathrm{~g}$ DW, and max. $45.57 \mathrm{mg} / 100 \mathrm{~g}$ DW, 


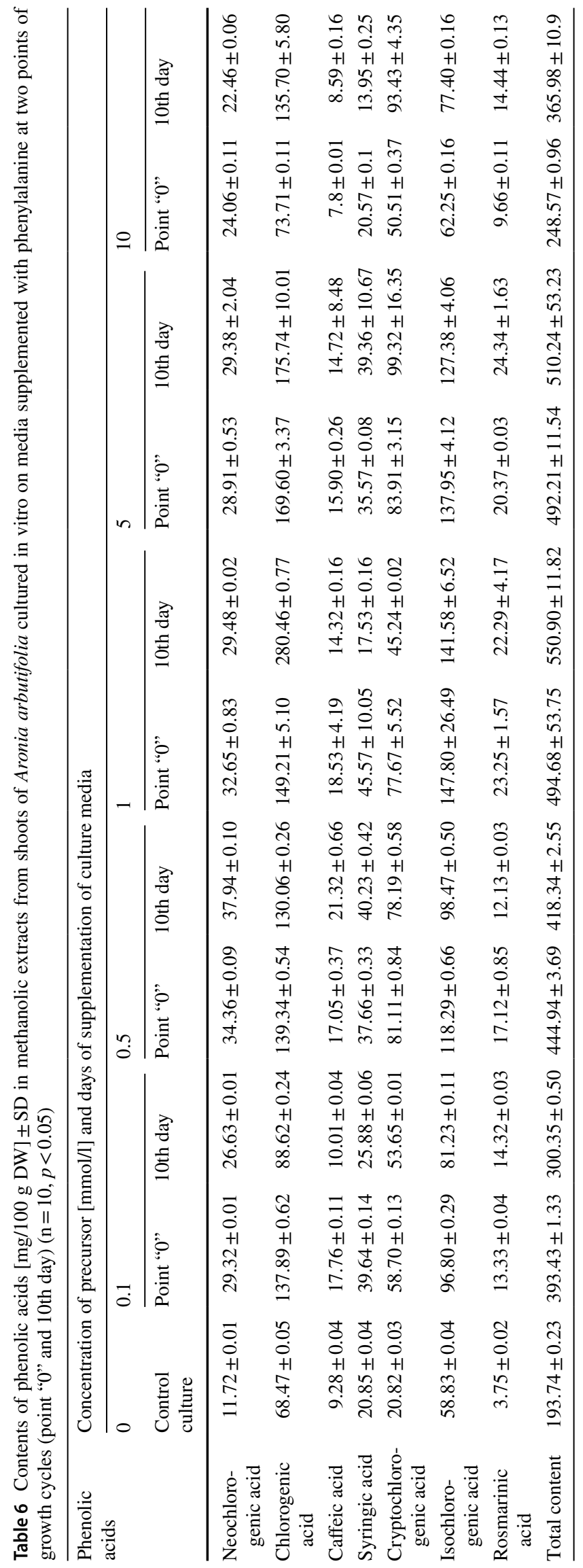


respectively. The smallest accumulated amounts were those of caffeic acid (max. $18.53 \mathrm{mg} / 100 \mathrm{~g} \mathrm{DW}$ ) and rosmarinic acid (max. $23.25 \mathrm{mg} / 100 \mathrm{~g} \mathrm{DW}$ ) (Table 6).

The total amounts of phenolic acids varied 1.7-fold depending on the precursor concentration, from 248.57 $(10 \mathrm{mmol} / \mathrm{l})$ to $494.68 \mathrm{mg} / 100 \mathrm{~g} \mathrm{DW}(1 \mathrm{mmol} / \mathrm{l})$. The highest amount was 2.6-fold higher than in control culture (Table 6).

\section{0th day of growth cycles}

Two depsides were accumulated in the analyzed extracts in the highest amounts-chlorogenic and isochlorogenic acid (Table 6). The amount of chlorogenic acid and isochlorogenic acid varied within wide limits, 3.2- and 1.8-fold depending on the precursor concentration: from $88.62(0.1 \mathrm{mmol} / \mathrm{l})$ to $280.46 \mathrm{mg} / 100 \mathrm{~g} \mathrm{DW}(1 \mathrm{mmol} / \mathrm{l})$, and from $77.40(10 \mathrm{mmol} / \mathrm{l})$ to $141.58 \mathrm{mg} / 100 \mathrm{~g} \mathrm{DW}$ $(1 \mathrm{mmol} / \mathrm{l})$, respectively. Cryptochlorogenic acid was accumulated in smaller but considerable amounts, from 45.24 ( $1 \mathrm{mmol} / \mathrm{l})$ to $99.32 \mathrm{mg} / 100 \mathrm{~g} \mathrm{DW}(5 \mathrm{mmol} / \mathrm{l})$. The amount of syringic acid was much lower, max. $40.23 \mathrm{mg} / 100 \mathrm{~g}$ DW $(0.5 \mathrm{mmol} / \mathrm{l})$. The lowest accumulated amounts were those of neochlorogenic acid (max. $37.94 \mathrm{mg} / 100 \mathrm{~g} \mathrm{DW}$ ), rosmarinic acid (max. $24.34 \mathrm{mg} / 100 \mathrm{~g}$ DW) and caffeic acid (max. $21.32 \mathrm{mg} / 100 \mathrm{~g} \mathrm{DW}$ ) (Table 6).

The total amounts of phenolic acids varied 1.8-fold depending on the concentration of phenylalanine, from $300.35(0.1 \mathrm{mmol} / \mathrm{l})$ to $550.90 \mathrm{mg} / 100 \mathrm{~g} \mathrm{DW}(1 \mathrm{mmol} / \mathrm{l})$. The maximal value was 2.8 -fold higher than in control culture and only 1.1-fold higher than after addition of precursor at point " 0 " (Table 6).

\section{Effect of feeding with cinnamic acid}

\section{Biomass increments}

The addition of cinnamic acid into the culture media at point " 0 " in the concentrations of $0.1-1.0 \mathrm{mmol} / \mathrm{l}$ resulted in high dry biomass increments (8.2-9.1-fold). Only the highest concentrations of this precursor stopped the growth of the shoots (1.5- and 1.3 -fold increments for 5 and $10 \mathrm{mmol} / \mathrm{l}$, respectively). The addition of cinnamic acid at 10th day of cultures in the range $0.1-5 \mathrm{mmol} / \mathrm{l}$ stimulated the biomass increments (8.4-8.9-fold increments) which were higher than in the control culture. Only the highest amount of this precursor $(10 \mathrm{mmol} / \mathrm{l})$ was not so beneficial; 5.0 -fold increments were documented (Table 1, Fig. S6).

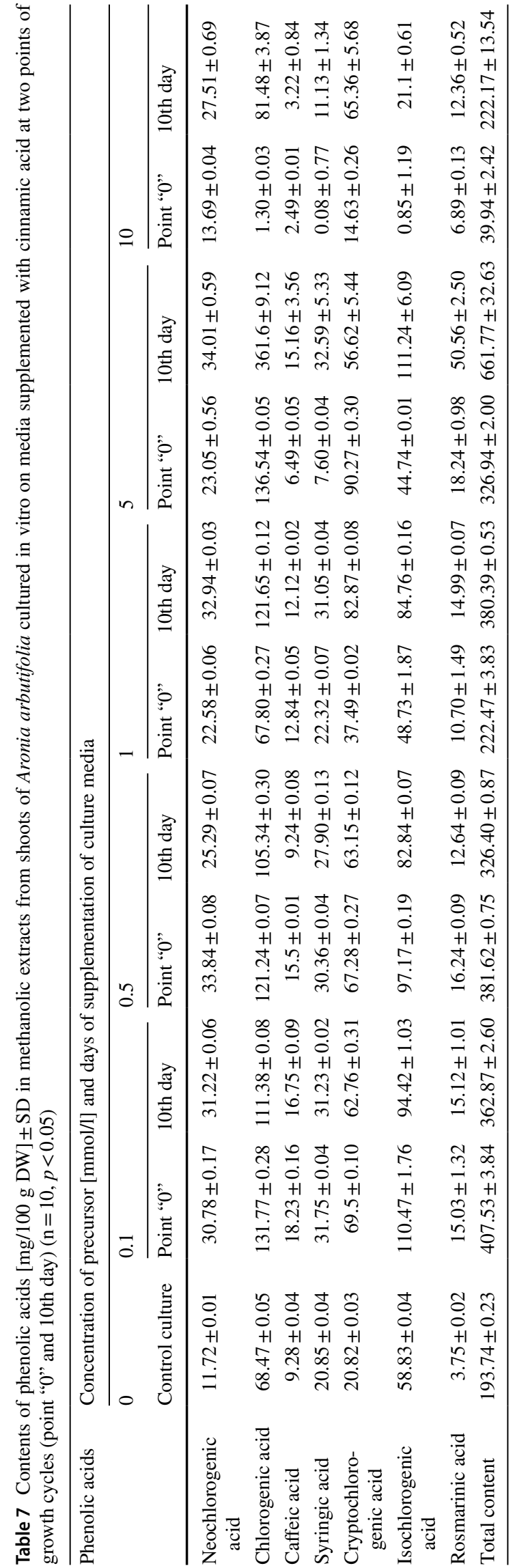




\section{Accumulation of metabolites}

\section{Point " 0 "-1st day of growth cycles}

After addition of cinnamic acid the same two depsides were also the main compounds-chlorogenic and isochlorogenic acid (Table 7). Their amounts varied even 102.0 and 130.0fold depending on the concentration of the precursor, ranging from $1.30 \mathrm{mg} / 100 \mathrm{~g} \mathrm{DW}(10 \mathrm{mmol} / \mathrm{l})$ to $136.54 \mathrm{mg} / 100 \mathrm{~g}$ DW ( $5 \mathrm{mmol} / \mathrm{l})$, and from $0.85 \mathrm{mg} / 100 \mathrm{~g} \mathrm{DW}(10 \mathrm{mmol} / \mathrm{l})$ to $110.47 \mathrm{mg} / 100 \mathrm{~g} \mathrm{DW}(0.1 \mathrm{mmol} / \mathrm{l})$, respectively.

Cryptochlorogenic acid showed relatively high amounts (14.63 (10 mmol/l)—90.27 mg/100 g DW (5 mmol/l)). Syringic acid was accumulated in much smaller amount: max. $31.75 \mathrm{mg} / 100 \mathrm{~g} \mathrm{DW}(0.1 \mathrm{mmol} / \mathrm{l})$. The highest neochlorogenic acid content was also comparable- $33.84 \mathrm{mg} / 100 \mathrm{~g}$ DW $(0.5 \mathrm{mmol} / \mathrm{l})$. Rosmarinic acid and caffeic acid were accumulated in the smallest amounts (max. $18.24 \mathrm{mg} / 100 \mathrm{~g}$ DW and $18.28 \mathrm{mg} / 100 \mathrm{~g} \mathrm{DW}$, respectively) (Table 7).

The total amount of the compounds increased greatly10.2-fold, depending on the precursor concentration, from $39.94 \mathrm{mg} / 100 \mathrm{~g} \mathrm{DW}(10 \mathrm{mmol} / \mathrm{l})$ to a maximum value of $407.53 \mathrm{mg} / 100 \mathrm{~g}$ DW $(0.1 \mathrm{mmol} / \mathrm{l})$. The highest total amount was 2.1-fold higher than in control culture (Table 7).

\section{0th day of growth cycles}

Chlorogenic acid was accumulated in the largest amounts (81.48 (10 mmol/l) - $361 \mathrm{mg} / 100 \mathrm{~g} \mathrm{DW} \mathrm{(5} \mathrm{mmol/l)).} \mathrm{Isochlo-}$ rogenic acid $(21.10(10 \mathrm{mmol} / \mathrm{l})-111.24 \mathrm{mg} / 100 \mathrm{~g} \mathrm{DW})$ and cryptochlorogenic acid $(56.62(5 \mathrm{mmol} / \mathrm{l})-82.87 \mathrm{mg} / 100 \mathrm{~g}$ DW) were also accumulated in considerable amounts (Table 7). The highest amount of rosmarinic acid$50.56 \mathrm{mg} / 100 \mathrm{~g} \mathrm{DW}(5 \mathrm{mmol} / \mathrm{l})$ —was significant higher than the highest amounts of the remaining three compounds, neochlorogenic, syringic and caffeic acids (34.01, 32.59 and $16.75 \mathrm{mg} / 100 \mathrm{~g} \mathrm{DW}$, respectively) (Table 7).

The maximal total amount of all 7 compounds was observed after addition of the precursor at a concentration of $5 \mathrm{mmol} / \mathrm{l}(661.77 \mathrm{mg} / 100 \mathrm{~g} \mathrm{DW})$. The lowest amount was recorded after adding the precursor at a concentration of $10 \mathrm{mmol} / \mathrm{l}(222.17 \mathrm{mg} / 100 \mathrm{~g} \mathrm{DW})$. The maximal value was 3.4-fold higher than in control culture and 1.6-fold higher than after addition of cinnamic acid at point "0" (Table 7).

\section{Effect of feeding with benzoic acid}

\section{Biomass increments}

The supplementation of the culture media with benzoic acid at two points of time-at point " 0 " in the range $0.1-1 \mathrm{mmol} / 1$ and at 10th day of growth cycles in all concentrations resulted in beneficial effect of the dry biomass

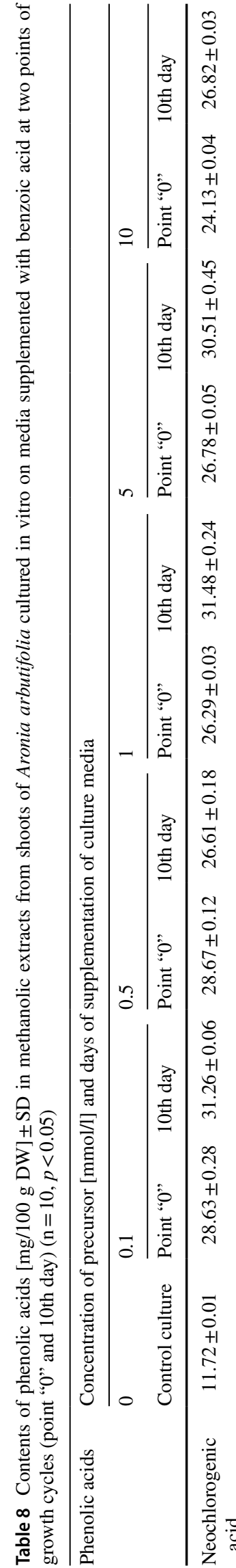

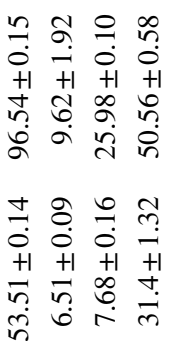

5
0
+1
$\stackrel{1}{c}$
$\dot{b}$

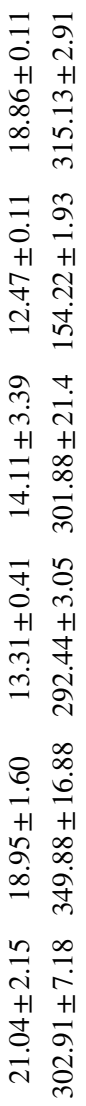

$\vec{\infty} \vec{n} \infty \vec{\infty}$

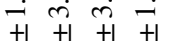

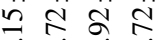

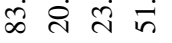

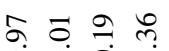

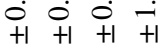

$\vec{n} \infty \stackrel{0}{\infty}$

ì

స $\sigma \infty$

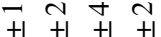

$\cap \infty \infty_{\infty}^{\infty} \infty$

مᄋ

tके $\bar{a}$

$\begin{array}{lll}0 \\ +1\end{array}++1+1$

च to

㐫 đं

ๆ $\overline{0} \infty$

$\begin{array}{llll}0 & 0 & 0 & 0 \\ +1 & +1 & +1 & +1\end{array}$

ते ते

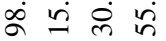

ปย สิ

$\begin{array}{llll} & 0 & & 0 \\ 0 & 0 & 0 & 0 \\ +1 & +1 & +1\end{array}$

\& 다요

मूं ले

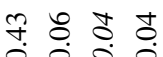

$\begin{array}{lll} \\ +1\end{array}+1+1+1$

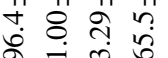

ฉू ले है

중

$\begin{array}{lll}2 \\ +1\end{array}+1+1$

m f $\infty$

$\infty=\underset{0}{0}$

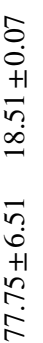

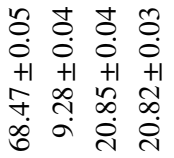

ชิ กิ

0
$0+1$
$0+1$

$\therefore$

ले
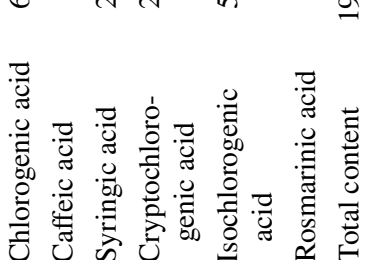
increments; 8.4-9.3-fold increments were confirmed on 20th day of growth cycles. Only at the highest concentration - 5 and $10 \mathrm{mmol} / \mathrm{l}$ of precursor which was added at point " 0 ", 5.5- and 2.0-fold increments of biomass, respectively was documented (Table 1, Fig. S7).

\section{Accumulation of metabolites}

\section{Point " 0 " -1 st day of growth cycles}

The compounds accumulated in largest quantities were chlorogenic and isochlorogenic acid (Table 8). The amounts of these compounds varied 2.1- and 5.1-fold depending on the precursor concentrations, in the ranges 53.51 (10 mmol/l) - $112.51 \mathrm{mg} / 100 \mathrm{~g} \mathrm{DW}(5 \mathrm{mmol} / \mathrm{l})$, and 18.51 $(10 \mathrm{mmol} / \mathrm{l})-93.84 \mathrm{mg} / 100 \mathrm{~g} \mathrm{DW}(0.5 \mathrm{mmol} / \mathrm{l})$, respectively. The amount of cryptochlorogenic acid were also high, ranging from $27.31(5 \mathrm{mmol} / \mathrm{l})$ to $69.06 \mathrm{mg} / 100 \mathrm{~g}$ DW $(0.5 \mathrm{mmol} / \mathrm{l})$. The amounts of neochlorogenic acid (24.13-28.67 mg/100 g DW) remained almost at the same level. The amounts of syringic acid reached the maximal of about $32 \mathrm{mg} / 100 \mathrm{~g} \mathrm{DW}(5 \mathrm{mmol} / \mathrm{l})$. The smallest accumulated amounts were those of rosmarinic acid (max. $21.04 \mathrm{mg} / 100 \mathrm{~g}$ DW) and caffeic acid (max. $17.83 \mathrm{mg} / 100 \mathrm{~g}$ DW) (Table 8).

The total amounts of the 7 metabolites increased more than 2.2 -fold, from $154.22 \mathrm{mg} / 100 \mathrm{~g} \mathrm{DW}(10 \mathrm{mmol} / \mathrm{l})$ to $345.01 \mathrm{mg} / 100 \mathrm{~g} \mathrm{DW}(0.5 \mathrm{mmol} / \mathrm{l})$ and the maximal total content increased 1.8-fold in comparison with the control culture (Table 8).

\section{0th day of growth cycles}

Chlorogenic and isochlorogenic acid were also the main compounds in the analyzed shoot extracts (Table 8). The amounts of chlorogenic acid were almost constant (96.40-98.70 mg/100 g DW), except for extracts from the shoots grown on a medium supplemented with the precursor at $5 \mathrm{mmol} / \mathrm{l}(83.15 \mathrm{mg} / 100 \mathrm{~g} \mathrm{DW})$. The amounts of isochlorogenic acid varied more, 1.2-fold from $77.75 \mathrm{mg} / 100 \mathrm{~g} \mathrm{DW}(5 \mathrm{mmol} / \mathrm{l})$ to $95.17 \mathrm{mg} / 100 \mathrm{~g} \mathrm{DW}$ (0.1 mmol/1). Relatively high amounts of cryptochlorogenic acid (50.56-65.5 mg/100 g DW) were documented. Neochlorogenic and syringic acids were accumulated in the shoots in similar amounts (max. 31.48 and $33.29 \mathrm{mg} / 100 \mathrm{~g}$ DW, respectively). The highest levels of rosmarinic acid $(18.95 \mathrm{mg} / 100 \mathrm{~g} \mathrm{DW})$ and caffeic acid $(20.72 \mathrm{mg} / 100 \mathrm{~g} \mathrm{DW})$ were also very similar.

The total amounts of the 7 metabolites varied slightly (1.2-fold), from 301.88 ( $5 \mathrm{mmol} / \mathrm{l})$ to $349.88 \mathrm{mg} / 100 \mathrm{~g} \mathrm{DW}$ ( $1 \mathrm{mmol} / \mathrm{l})$; however, the max. value was 1.8 -fold higher than in the control cultures (193.74 mg/100 g DW). This

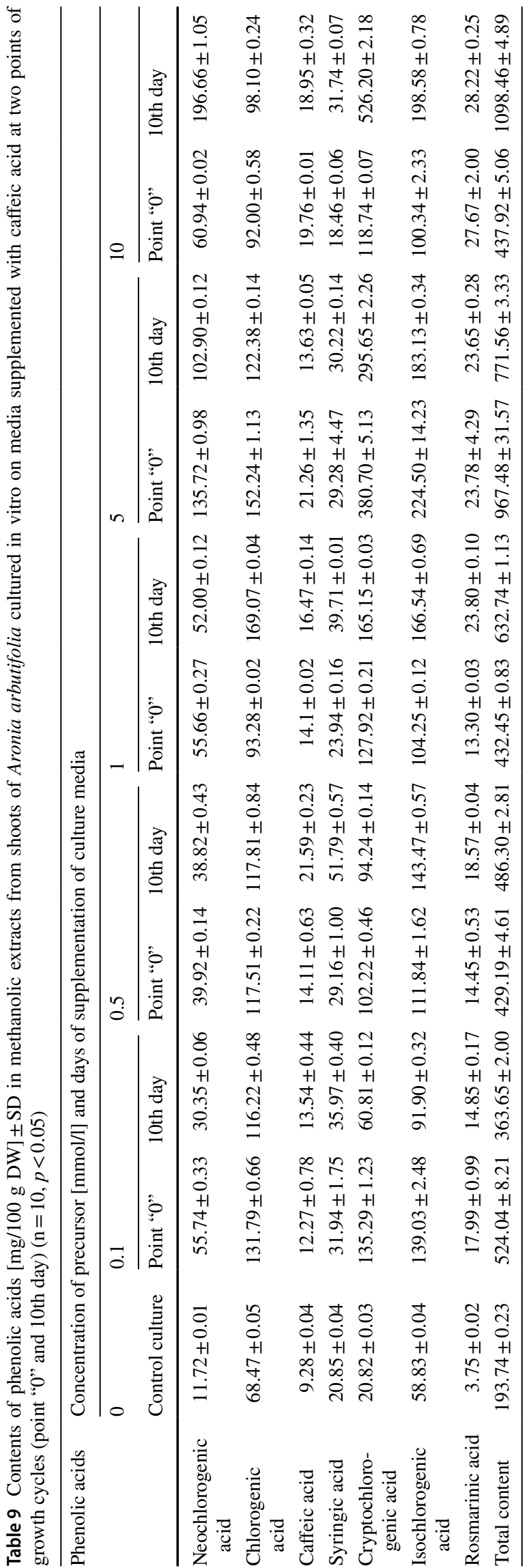


value reached the same level as after addition of the precursor at point " 0 " (Table 8).

\section{Effect of feeding with caffeic acid}

\section{Biomass increments}

The addition of caffeic acid at all tested concentrations haven't negative effect on the dry biomass increments. The increments varied from 5.6- to 8.4-fold, after the addition of precursor at point " 0 " and from 7.6- to 8.8-fold after its addition on 10th day of culture (Table 1, Fig. S8).

\section{Accumulation of metabolites}

\section{Point " 0 "-1st day of growth cycles}

Three depsides-chlorogenic, isochlorogenic and cryptochlorogenic acids-were present in the highest amount (Table 9). The amounts of chlorogenic acid ranged 1.7-fold from 92.00 (10 mmol/l) to $152.24 \mathrm{mg} / 100 \mathrm{~g} \mathrm{DW}(5 \mathrm{mmol} / \mathrm{l})$, whereas for isochlorogenic acid it changed 2.2-fold from $100.34(10 \mathrm{mmol} / \mathrm{l})$ to $224.50 \mathrm{mg} / 100 \mathrm{~g} \mathrm{DW}(5 \mathrm{mmol} / \mathrm{l})$. Cryptochlorogenic acid content varied 3.7-fold from 102.22 $(0.5 \mathrm{mmol} / \mathrm{l})$ to a maximal value $380.70 \mathrm{mg} / 100 \mathrm{~g}$ DW (5 mmol/l). Another compound-neochlorogenic acidwas accumulated in smaller but considerable amounts (39.92-135.72 mg/100 g DW). Syringic acid was accumulated in much smaller amounts (max. $31.94 \mathrm{mg} / 100 \mathrm{~g} \mathrm{DW}$ ). The confirmed amounts of rosmarinic acid and caffeic acid were very similar, ranging from 13.30 to 27.67 and from 12.27 to $21.26 \mathrm{mg} / 100 \mathrm{~g} \mathrm{DW}$, respectively (Table 9).

The total amounts of the compounds varied 1.8-fold from $524.04 \mathrm{mg} / 100 \mathrm{~g} \mathrm{DW}(0.1 \mathrm{mmol} / \mathrm{l})$ to a value close to $1 \mathrm{~g} / 100 \mathrm{~g} \mathrm{DW}(967.48 \mathrm{mg} / 100 \mathrm{~g} \mathrm{DW}, 5 \mathrm{mmol} / \mathrm{l})$. The maximal total amount was 5.0-fold higher than in control culture (Table 9).

\section{0th day of growth cycles}

Similar to caffeic acid supplementation at point "0", the main compounds were three depsides - chlorogenic, isochlorogenic and cryptochlorogenic acids (Table 9). The first of these depsides was accumulated in amounts from 98.10 ( $10 \mathrm{mmol} / \mathrm{l})$ to $169.07 \mathrm{mg} / 100 \mathrm{~g}$ DW ( $1 \mathrm{mmol} / \mathrm{l})$. Similarly, the amount of the other 2 depsides varied within wide limits 2.2 - and 8.7 -fold; $91.90(0.1 \mathrm{mmol} / \mathrm{l})-198.58 \mathrm{mg} / 100 \mathrm{~g}$ DW $(10 \mathrm{mmol} / \mathrm{l})$, and $60.81(0.1 \mathrm{mmol} / \mathrm{l})-526.20 \mathrm{mg} / 100 \mathrm{~g}$ DW (10 mmol/l), respectively. The obtained amounts of neochlorogenic acid were also considerable, 102.90 and $196.66 \mathrm{mg} / 100 \mathrm{~g}$ DW at the highest precursor concentrations of 5 and $10 \mathrm{mmol} / \mathrm{l}$, respectively. At lower concentrations they ranged from 30.35 to $52.00 \mathrm{mg} / 100 \mathrm{~g}$ DW. The maximum confirmed amounts of the three remaining phenolic acids, i.e. syringic acid, rosmarinic acid and caffeic acid, were: $31.74(10 \mathrm{mmol} / \mathrm{l}), 28.22(10 \mathrm{mmol} / \mathrm{l})$ and $21.59(0.5$ mmol) mg/100 g DW, respectively (Table 9).

The total amount of the 7 metabolites was high, ranging 3.0-fold from $363.65 \mathrm{mg} / 100 \mathrm{~g} \mathrm{DW}(0.1 \mathrm{mmol} / \mathrm{l})$ to a value exceeding $1 \mathrm{~g} / 100 \mathrm{~g} \mathrm{DW}(1098.46 \mathrm{mg} / 100 \mathrm{~g} \mathrm{DW})$ with the maximum precursor concentration $(10 \mathrm{mmol} / \mathrm{l})$. The maximal value was even 5.7-fold higher than in control culture and only 1.1-fold higher than after addition of caffeic acid at point "0" (Table 9).

To sum up, the best result in stimulation of biosynthesis of phenolic acids in A. arbutifolia cultures were confirmed after feeding of the culture media with caffeic acid at concentrations of $10 \mathrm{mmol} / \mathrm{l}$ at 10 th day of culture growth and of $5 \mathrm{mmol} / 1$ at point " 0 " (about $1 \mathrm{~g} / 100 \mathrm{~g} \mathrm{DW}$ of total phenolic acids). They were 5.7- and 5.0-fold higher than in control culture. Enough good results were observed after feeding with cinnamic acid $(5 \mathrm{mmol} / \mathrm{l})$ and phenylalanine $(1 \mathrm{mmol} / \mathrm{l}$ ) also on 10th day (about 0.66 and $0.53 \mathrm{~g} / 100 \mathrm{~g}$ DW of total phenolic acids, respectively).

\section{Comparative statistical analysis}

Comparative statistical analysis was done by means of four-way ANOVA test, followed by Tukey post-hoc comparison (Table 10). The considered factors were: precursor concentration (6 levels), precursor (5 levels), day of culture enrichment (2 levels) and species (2 levels). Each result (biomass and 7 acids) was computed independently. The precursor concentration factor significance has limited cognitive value in this approach, because it gathers concentrations of all days, precursors and species. However, including this factor was necessary to give the information about respective concentrations. The concentration plays the analogous role like random effect in mixed-mode analysis, which-in this case would result in almost identical conclusions. After playing with ANOVA and mixedmode, we decided to present ANOVA results to show, that concentration of added precursor was always significant both for biomass and all acids, even not taking into the account the differences between particular precursors. It should be also explained, that we could not use concentration as a numerical variable (creating a regression model with other factorial variables), because the dependence between concentration and response is nonlinear and this approach would fail with insignificant slope when the response increases and then decreases again.

There were always significant differences between studied precursors. The least significant differences were obtained for biomass $(p=0.024)$. Multiple comparisons revealed that 
Table 10 Statistical analysis of obtained results by multi-way ANOVA followed by multiple comparisons by Tukey test

\begin{tabular}{llllll} 
Biomass & $\begin{array}{l}\text { Neochlorogenic } \\
\text { acid }\end{array}$ & $\begin{array}{l}\text { Chlorogenic } \\
\text { acid }\end{array}$ & Caffeic acid & Syringic acid $\begin{array}{l}\text { Cryp- } \\
\text { tochloro- } \\
\text { genic acid }\end{array}$ & $\begin{array}{l}\text { Isochlorogenic } \\
\text { acid }\end{array}$ \\
& & & Rosmarinic acid \\
\hline
\end{tabular}

\begin{tabular}{|c|c|c|c|c|c|c|c|c|}
\hline \multicolumn{9}{|l|}{$\begin{array}{l}\text { Four-way } \\
\text { ANOVA test } \\
(p \text {-values })\end{array}$} \\
\hline Concentration & $1.3 e-09$ & 0.0049 & $9.6 e-10$ & $3.8 \mathrm{e}-07$ & $5.1 \mathrm{e}-10$ & 0.00044 & $1.4 \mathrm{e}-06$ & 0.016 \\
\hline Precursor & 0.024 & $4.7 e-11$ & $6 e-05$ & $2 \mathrm{e}-06$ & 0.00045 & $3.2 \mathrm{e}-09$ & $9.9 \mathrm{e}-12$ & 0.00085 \\
\hline Day & $5.9 \mathrm{e}-05$ & 0.00077 & 0.00076 & 0.91 & 0.064 & 0.17 & $3.3 e-06$ & 0.46 \\
\hline Species & 0.11 & $2.1 \mathrm{e}-24$ & 0.76 & 0.002 & 0.19 & $2.7 \mathrm{e}-05$ & 0.00064 & 0.00011 \\
\hline \multicolumn{9}{|c|}{ Tukey post-hoc test between species $(m-a)$} \\
\hline Difference & -0.555 & 57.4 & -2.45 & -2.15 & 2.04 & -43.1 & 21.7 & 14.6 \\
\hline $\begin{array}{l}\text { Lower } 95 \% \\
\text { bound }\end{array}$ & -1.25 & 48.1 & -18.6 & -3.49 & -1.03 & -62.8 & 9.38 & 7.34 \\
\hline $\begin{array}{l}\text { Upper } 95 \% \\
\text { bound }\end{array}$ & 0.136 & 66.7 & 13.7 & -0.798 & 5.11 & -23.4 & 33.9 & 21.8 \\
\hline Adjusted $\mathrm{p}$ value & 0.114 & $2 \mathrm{e}-16$ & 0.765 & 0.00199 & 0.192 & $2.7 \mathrm{e}-05$ & 0.000639 & 0.000106 \\
\hline \multicolumn{9}{|c|}{ Tukey post-hoc test between days $(10-0)$} \\
\hline Difference & 1.46 & 15.9 & 27.8 & 0.075 & 2.86 & 13.7 & 29.7 & 2.71 \\
\hline $\begin{array}{l}\text { Lower } 95 \% \\
\text { bound }\end{array}$ & 0.772 & 6.65 & 11.6 & -1.27 & -0.211 & -5.96 & 17.4 & -4.53 \\
\hline $\begin{array}{l}\text { Upper } 95 \% \\
\text { bound }\end{array}$ & 2.15 & 25.2 & 44 & 1.42 & 5.93 & 33.5 & 41.9 & 9.94 \\
\hline Adjusted p value & $7 e-05$ & 0.000883 & 0.000876 & 0.913 & 0.0677 & 0.17 & $4.19 e-06$ & 0.461 \\
\hline \multicolumn{9}{|l|}{$\begin{array}{l}\text { Tukey post-hoc } \\
\text { test between } \\
\text { precursors } \\
\text { (differences } \\
\text { given where } \\
\text { siginificant) }\end{array}$} \\
\hline $\begin{array}{l}\text { Benzoic acid- } \\
\text { phenylalanine }\end{array}$ & & & -43.3 & -3.86 & & & -26.1 & \\
\hline $\begin{array}{l}\text { Cinnamic acid - } \\
\text { phenylalanine }\end{array}$ & -1.51 & & & & & & & 15.8 \\
\hline $\begin{array}{l}\text { Caffeic acid - } \\
\text { phenylalanine }\end{array}$ & & 41.8 & & & & 81.3 & 37 & \\
\hline $\begin{array}{l}\text { Cinnamic acid - } \\
\text { benzoic acid }\end{array}$ & & & 53.9 & 2.95 & & & & 17.5 \\
\hline $\begin{array}{l}\text { Caffeic acid- } \\
\text { benzoic acid }\end{array}$ & & 47.7 & & 5.36 & 8.2 & 81.2 & 63.2 & 14.9 \\
\hline $\begin{array}{l}\text { Caffeic acid- } \\
\text { cinnamic acid }\end{array}$ & & 34 & & & 8.07 & 81.8 & 60.5 & \\
\hline
\end{tabular}

the significant difference is observed only between cinnamic acid (lowest biomass growth) and phenylalanine (highest biomass growth). For most of analyzed compounds, caffeic acid yields significantly higher amounts than benzoic and cinammic acids. Phenylalanine yields always significantly higher amount of all compounds than one of three acids: benzoic, caffeic and cinnamic. The significant difference between cinnamic and benzoic acids can be confirmed only for three compounds.

The significant differences between days of media enrichment (10th day was always better) can be noted for biomass and all studies parameters except caffeic and cryptochlorogenic acids. Regarding species, the situation is quite complex. A. melanocarpa gave slightly lower biomass at all 
conditions (insignificant difference). Significantly higher amount of neochlorogenic, isochlorogenic and rosmarinic acids was observed in this plant. On the contraty, the content of caffeic and cryptochlorogenic acids was significantly lower. No significant differences was observed for chlorogenic and syringic acid.

\section{Discussion}

Satisfactory increases in biomass were obtained in the experimental cultures of both tested Aronia species (Table 1, Figs. S1-S8). In black aronia cultures, inhibition of biomass growth was observed at high concentrations of cinnamic acid and benzoic acid ( 5 and $10 \mathrm{mmol} / \mathrm{l})$. Also the highest concentration of phenylalanine $(10 \mathrm{mmol} / \mathrm{l})$ added at point " 0 " inhibited the increases of shoot biomass. In red aronia cultures, high levels of cinnamic acid (5 and $10 \mathrm{mmol} / \mathrm{l})$ and also the highest tested concentration of benzoic acid $(10 \mathrm{mmol} / \mathrm{l})$ affected biomass growth adversely (Table 1$)$. It can be supposed that (due to the acidic nature of benzoic and cinnamic acids), their addition in higher concentrations changed the $\mathrm{pH}$ of the culture media below some threshold, inhibiting biomass growth.

In the control cultures of both species, and also in their experimental cultures, the presence of particular metabolites was identical. All the extracts analyzed were confirmed to contain as many as 5 depsides (neochlorogenic, chlorogenic, cryptochlorogenic, isochlorogenic and rosmarinic acids) and two phenolic acids-syringic and caffeic acids (Tables 2, 3, $4,5,6,7,8,9$ ).

Interestingly, in the agitated cultures of both aronias, structurally more complex compounds were created, i.e. depsides, and not simple phenolic acids-derivatives of cinnamic acid, benzoic acid and/or derivatives of phenylacetic acid. It was chlorogenic, isochlorogenic and neochlorogenic acids that were the quantitatively dominant compounds in the agitated cultures of black aronia. The compounds produced in stationary (agar) cultures of this species were mainly hydroxycinnamic acids (Szopa et al. 2013, 2018c; Szopa and Ekiert 2014).

By comparison, in shoot stationary (agar) cultures of red aronia, the quantitatively dominant compounds were another depsides: chlorogenic, rosmarinic and neochlorogenic acids (Szopa et al. 2018c). In the currently analyzed agitated cultures, the amounts of rosmarinic acid were among the lowest. Cell metabolism was mainly geared towards the production of chlorogenic, isochlorogenic and cryptochlorogenic acids.

The influence of the type of in vitro cultures on the presence and accumulated amounts of individual metabolites is a known phenomenon in plant biotechnology (Charlwood et al. 1990). Such dependency was proved by us in our earlier research, based on stationary liquid and agitated shoot cultures of Ruta graveolens and with stationary liquid and agitated shoot-differentiating cultures of $R$. graveolens ssp. divaricata maintained on LS-media variants (Ekiert et al. 2001, 2005; Ekiert and Czygan 2005). We confirmed the presence of the same linear furanocoumarins and umbelliferone in both cultures. The quantities of the most of metabolites were different in stationary and agitated cultures of both plants. Higher amounts were confirmed in stationary cultures.

In our last experiments with Scutellaria lateriflora and S. baicalensis in vitro shoot cultures we observed the differences in the quality of metabolites (specific Scutellaria flavonoids, phenolic acids and verbascoside) between agar and agitated cultures maintained on MS medium variants. The higher amounts of metabolites were confirmed also in stationary (agar) culture. On the other hand on LS media variants the presence of the same compounds was confirmed in agar and agitated cultures. The quantities of metabolites were higher in agar cultures (Kawka et al. 2019, 2020).

In the experiments on microshoot in vitro cultures of Schisandra chinensis (Szopa et al. 2016) and its cultivar S. chinensis cv. Sadova (Szopa et al. 2018a), the accumulation of dibenzocyclooctadiene lignans between stationary agar and agitated cultures. The highest lignan contents for both Schisandra microshoot cultures, were found in biomass extracts from agar cultures, max. $237.86 \mathrm{mg} / 100 \mathrm{~g}$ DW and $490.25 \mathrm{mg} / 100 \mathrm{~g}$ DW, respectively (Szopa et al. 2019).

The aim of the present study, was to stimulate phenolic acids production in shoot cultures of two aronias. Our former studies showed that agitated aronia cultures are capable of producing especially high amounts of depsides (chlorogenic, rosmarinic and neochlorogenic acids). Phenolic acids are considered fundamentally to be cinnamic and benzoic acids derivatives (Raffauf 1983; Natella et al. 1999). We choose for the precursor feeding experiment these two simple and cheap mother compounds, as they are direct biosynthetic precursors of phenolic acids. Phenylalanine is an earlier step in the biosynthetic pathway of phenolic acids. We decided to test this amino acid as the potentially good precursor of phenolic acids, too. Phenylalanine is the key intermediate in biosynthesis of different groups of metabolites and is often used to stimulate the biosynthesis of phenolic acids, flavonoids, lignans, phenylethanolic glycosides and other compounds of phenylpropanoid pathways.

In our current experiments, the most effective proved to be the addition of cinnamic acid. In in vitro cultures of black and red aronias, a concentration of $5 \mathrm{mmol} / \mathrm{l}$ was found to cause a very high increase in the total amount of all 7 metabolites-3.41 and 3.42 times, respectively. The resulting total amounts of about 990 and $662 \mathrm{mg} / 100 \mathrm{~g}$ DW were interesting from a practical point of view (Tables 3 and 7 , Fig. 1). These results are not surprising. Cinnamic acid is 


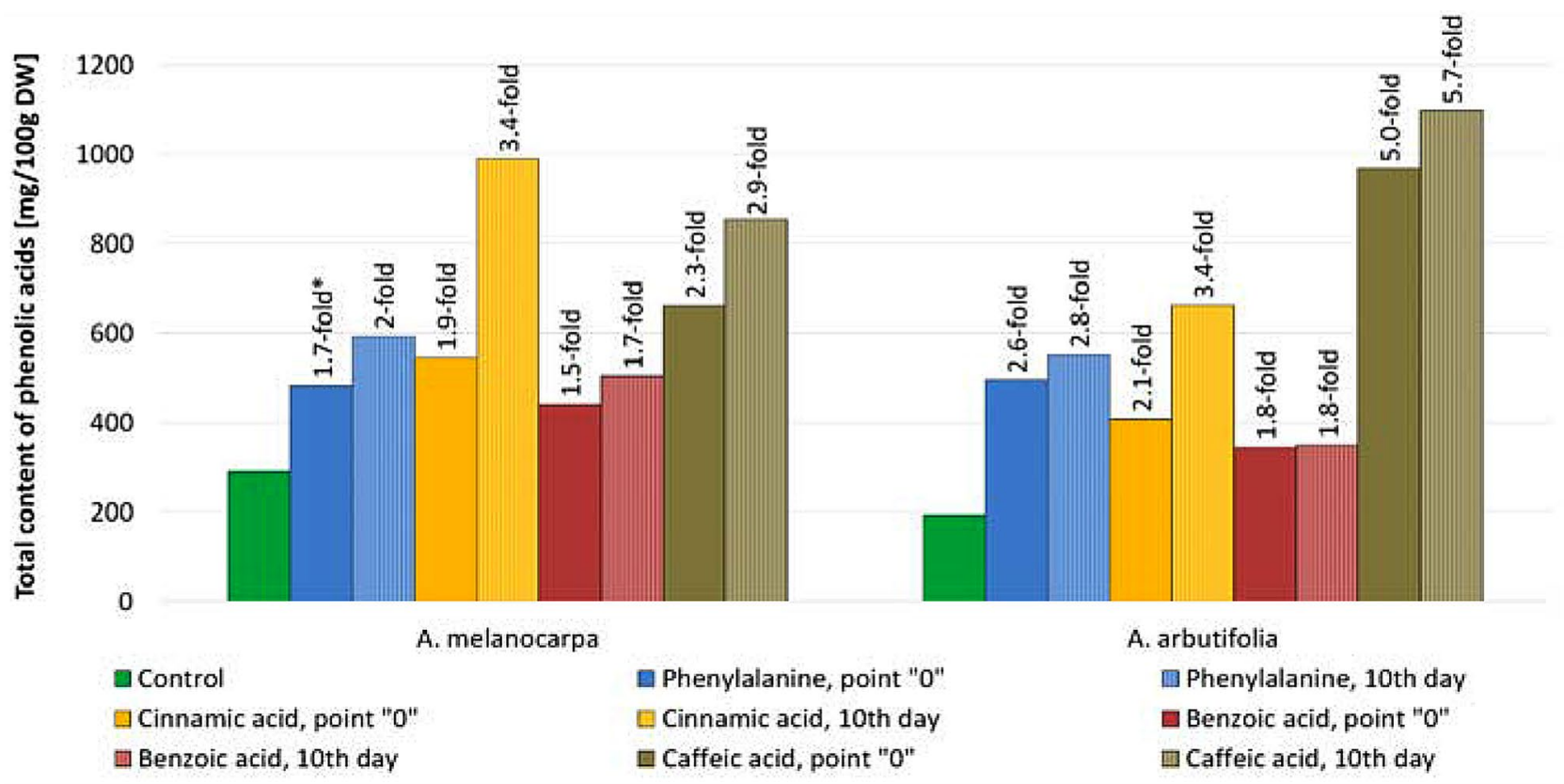

Fig. 1 The maximal total amounts of phenolic acids obtained in $A$. melanocarpa and A. arbutifolia agitated cultures after addition of precursors, in different concentrations $(0.1-10.0 \mathrm{mmol} / \mathrm{l})$, at point " 0 "

also involved into phenylpropanoid biosynthetic pathways (Petersen and Simmonds 2003; Gramazio et al. 2014) Cinnamic acid has been concerned as effective to increase total phenolic acid production based on research on Salvia splendens plants (McCalla and Neish 1959). The cinnamic acid feeding experiment was applied in order to increase production of such phenolic acids like p-coumaric and ferulic acids in Larrea divaricata cell cultures. The highest production of phenolic acids was achieved after $0.5 \mu \mathrm{M}$ of cinnamic acid supplementation at the first day of culture growth. The content of p-coumaric and ferulic acids were equal c.a. 225 and $50 \mu \mathrm{g} / \mathrm{g}$ DW, respectively (Palacio et al. 2011). Moreover, cinnamic acid was recognized as good precursor of flavonoids biosynthesis in cell suspension cultures of Saussurea medusa (Lu et al. 2001). It was used also as the effective precursor of other bioactive compounds, e.g. in in vitro immobilized placental tissues of Capsicum frutescens, in order to enhance the levels of capsaicinoids (Sudhakar Johnson and Ravishankar 1996) or in callus cultures of Psoralea corylifolia for increase of psoralen production (Parast et al. 2011).

The addition of two other precursors-benzoic acid and phenylalanine-resulted in significantly smaller increases in the amounts of the 7 compounds estimated, mainly depsides. The best results with benzoic acid were obtained after using it at a concentration of $1 \mathrm{mmol} / \mathrm{l}$, at which the total metabolite amounts increased 1.73-fold (black aronia) and 1.81-fold (red aronia). The maximum total amounts were approx. 503 and $350 \mathrm{mg} / 100 \mathrm{~g} \mathrm{DW}$, respectively (Tables 4, 8, Fig. 1). and on 10th day of culture into the media. *The added values present the increase in total contents of phenolic acids in comparison to control cultures

Benzoic acid (added in the second day, in concentration $100 \mu \mathrm{M}$ ) was used as an effective precursor of salicylic acid biosynthesis (max. $16 \mu \mathrm{g} / \mathrm{g} \mathrm{FW}$ ) in cell suspensions of Nicotiana tabacum cv. Samsun NN (Chong et al. 2001). Benzoic acid was also the good precursor for production of diterpenoid alkaloid-taxol in Taxus cuspidata in vitro cultures; the most effective concentrations of precursor were: 0.2 and $1 \mathrm{mM}$ for callus and $0.05,0.1$, and $0.2 \mathrm{mM}$ for suspensions. The highest increase of taxol production (from 2 to $10 \mu \mathrm{g} / \mathrm{g}$ DW) was achieved for suspension cultures (Fett-Neto et al. 1994).

In the current experiment with black and red aronias the best effect with phenylalanine was obtained after using its lowest concentrations, $0.1 \mathrm{mmol} / \mathrm{l}$ (black aronia) and $1.0 \mathrm{mmol} / \mathrm{l}$ (red aronia). The results were respectively, 2.0 times and 2.8 times higher than in the control cultures of both species (Tables 2 and 6, Fig. 1). Similar results, about 2.3 -fold increase in the yield of total flavonoid-quercetin (free and bound) was confirmed after addition of phenylalanine into cell cultures of Citrullus colocynthis. The best results were obtained also by lower tested concentrations of precursor (50 and $25 \mathrm{mg} / 100 \mathrm{ml})-7.25$ and $5.46 \mathrm{mg} / \mathrm{g} \mathrm{DW}$, respectively. Similar to our experiments with aronias, higher concentration of phenylalanine (75 and $100 \mathrm{mg} / 100 \mathrm{ml})$ were less beneficial for quercetin production (Chand Meena et al. 2014). A little better results than ours more than threefold increase in quercetin production were obtained in $\mathrm{Abu}$ tilon indicum culture after supplementation of the media 
with higher concentration of precursor- $-75 \mathrm{mg} / 100 \mathrm{ml}$ of phenylalanine. In this experiments phenylalanine was tested in the same concentrations like in above-mentioned investigations (25; 50; 75 and $100 \mathrm{mg} / 100 \mathrm{ml}$ ) (Sajjalaguddam and Paladugu 2015). Results of these two teams indicated, that the best concentration of precursor should be tested experimentally for each in vitro culture. Significant better results in comparison with ours were obtained in suspension culture of Linum flavum after enrichment of culture media with phenylalanine (3.5-fold increase in lignan-5-methoxypodophyllotoxin production) (van Uden et al. 1990). On the other hand feeding the cell culture of Cistanche deserticola with phenylalanine $(0.2 \mathrm{mmol})$ resulted only in max. $75 \%$ higher production of phenylethanoid glycosides $(1.1 \mathrm{~g} / \mathrm{l})$ (Ouyang et al. 2005).

In our earlier results with agitated in vitro cultures of black aronia, very interesting results were obtained after using caffeic acid (unpublished). For black aronia the main metabolites were depsides. Caffeic acid is one structure unit which builds the final structure of depsides, and this was the reason to test for the first time the supplementation of culture media with this phenolic acid. It was a good decision, because the increase in production of depsides was very satisfied, especially in red aronia culture. In the red aronia cultures at a concentration of $5 \mathrm{mmol} / \mathrm{l}$, this precursor caused an unusually high increase in the amounts of phenolic acids, mainly depsides—5.67 times (Table 9, Fig. 1). Caffeic acid was used by the cells from in vitro cultures of red aronia to produce depsides, especially chlorogenic, isochlorogenic and cryptochlorogenic acids. In the case of in vitro cultures of black aronia, an increase in the total concentration of the estimated compounds was also observed after the addition of caffeic acid; it was the highest also at a concentration of $5 \mathrm{mmol} / \mathrm{l}$, which caused a 2.95 -fold increase in metabolite content, most of all depsides: neochlorogenic, chlorogenic, cryptochlorogenic, isochlorogenic and rosmarinic acids (Table 5, Fig. 1). The maximum amount of metabolites obtained after addition of caffeic acid were very high, approx. 1098 and $855 \mathrm{mg} / 100 \mathrm{~g} \mathrm{DW}$ for red and black aronias, respectively (Tables 5, 9, Fig. 1).

The conducted experiments also proved that better production effects can be obtained after supplementation of the culture media with precursors on the 10th day of the growth cycle of both Aronia species. Compared to the administration of the precursors at point " 0 ", higher results can be obtained (Tables 2, 3, 4, 5, 6, 7, 8, 9, Fig. 1). The above-given maximal total amounts of the compounds were obtained after administering the precursors on the 10th day of the growth cycles. The 10-day period allowed in vitrogrown aronia shoots to "acclimatize" in the agitated cultures and subsequently to produce and accumulate bioactive compounds in significant amounts.

In the cultures of both aronias the differences in the total amounts of phenolic acids after application of precursors at point "0" and at 10th day of cultures were significant (Fig. 1). After application of phenylalanine and benzoic acid the difference were not very big (Tables 2, 4, 6, 8). On the other hand after addition of cinnamic acid they were higher (Tables 3 and 7, Fig. 1). When the media were supplemented with caffeic acid on 10th day in black aronia culture 2.9fold increase of total phenolic acids were confirmed, but in red aronia culture even 5.7-fold increase were observed. For red aronia culture we can propose as the best conditions for total production of phenolic acids the addition of caffeic acid at point " 0 " or at 10th day of culture at concentration $5 \mathrm{mmol} / \mathrm{l}$ and $10 \mathrm{mmol} / \mathrm{l}(0.97 \mathrm{~g} / 100 \mathrm{~g} \mathrm{DW}$ and $1.10 \mathrm{~g} / 100 \mathrm{~g}$ DW, respectively) and for black aronia the addition of cinnamic acid at 10th day of culture at concentration $5 \mathrm{mmol} / \mathrm{l}$ $(0.99 \mathrm{~g} / 100 \mathrm{~g} \mathrm{DW})$ or of caffeic acid on 10th day of culture at concentration $5 \mathrm{mmol} / \mathrm{l}(0.86 \mathrm{~g} / 100 \mathrm{~g} \mathrm{DW})$.

Another important factor is the best day of addition of precursor, which should also be tested experimentally. For example in Cistanche deserticola culture the best results of production of phenylethanoid glycosides were obtained after addition of phenylalanine on 8th day of culture growth (Ouyang et al. 2005). In other experiments e.g. with Citrullus colocynthis (Chand Meena et al. 2014) and Abutilon indicum (Sajjalaguddam and Paladugu 2015) in which also phenylalanine was tested, it was added into the culture media at point " 0 ".

The strategy used-feeding of culture media with a biogenetic precursors-is a known method in plant biotechnology, which theoretically and practically makes possible to increase the production of bioactive compounds. The wide range of the experiments conducted by us (testing of 4 different precursors, each of them administered to culture media at 5 different concentrations in the range $0.1-10.0 \mathrm{mmol} / \mathrm{l}$ at 2 different points in time) allowed us not only to expand our theoretical knowledge, but also led to obtain potentially applicative results.

We propose black aronia cultures cultivated on MS medium ( $1 \mathrm{mg} / \mathrm{l} \mathrm{BA}, 1 \mathrm{mg} / \mathrm{l} \mathrm{NAA})$ with addition of cinnamic acid on day 10th at concentration $5 \mathrm{mmol} / \mathrm{l}$ as a rich source of isochlorogenic, neochlorogenic and chlorogenic acid. In turn, we propose red aronia cultures maintained on the same MS variant with addition of caffeic acid on day 10 , at concentration $10 \mathrm{mmol} / \mathrm{l}$ as a rich source of chlorogenic, neochlorogenic and cryptochlorogenic acids (Table 10, Fig. 1).

The compounds obtained in maximum quantities-the depsides: isochlorogenic, chlorogenic, neochlorogenic and cryptochlorogenic acids-are compounds with numerous, very valuable biological properties, such as antioxidative, 
anti-inflammatory, antimicrobial, hepatoprotective, cardioprotective, neuroprotective or anticancer (Nakatani et al. 2000; Sato et al. 2011; Liu et al. 2011; Thurow 2012; Meng et al. 2013; Naveed et al. 2018).

The tested precursors are cheap chemical compounds; their use in aronia cultures on a larger scale (bioreactorgrown cultures-temporary immersion systems, suitable for shoot cultures) seems to be a necessary next stage of the research.

Author contributions A. Szopa, P. Kubica and Aleksandra WalkowiczBożek carried out the experiments, compiled the data, performed the chemical and statistical analysis. H. Ekiert wrote the manuscript with support from A. Szopa and P. Kubica. Ł. Komsta revised text after the first review and performed the statistical analysis. All the authors read and approved the manuscript in its final form.

Funding This study was funded by grant number PL: K/ZDS/005614.

\section{Compliance with ethical standards}

Conflict of interest The authors declare that there are no conflicts of interests.

Open Access This article is licensed under a Creative Commons Attribution 4.0 International License, which permits use, sharing, adaptation, distribution and reproduction in any medium or format, as long as you give appropriate credit to the original author(s) and the source, provide a link to the Creative Commons licence, and indicate if changes were made. The images or other third party material in this article are included in the article's Creative Commons licence, unless indicated otherwise in a credit line to the material. If material is not included in the article's Creative Commons licence and your intended use is not permitted by statutory regulation or exceeds the permitted use, you will need to obtain permission directly from the copyright holder. To view a copy of this licence, visit http://creativecommons.org/licenses/by/4.0/.

\section{References}

Cai Y, Luo Q, Sun M, Corke H (2004) Antioxidant activity and phenolic compounds of 112 traditional Chinese medicinal plants associated with anticancer. Life Sci 74:2157-2184. https://doi. org/10.1016/j.lfs.2003.09.047

Chand Meena M, Kesh Meena R, Patni V (2014) Effect of elicitor on quercetin production in cell cultures of Citrullus colocynthis (Linn.) Schrad. Pharma Innov 2:18-23

Charlwood B, Charlwood S, Molina-Tores J (1990) Accumulation of secondary compounds by organized plant cultures. In: Charlwood BV, Rhodes MJC (eds) Secondary products from plant tissue cultures. Clarendon Press, Oxford, pp 167-200

Chong J, Pierrel MA, Atanassova R et al (2001) Free and conjugated benzoic acid in tobacco plants and cell cultures. Induced accumulation upon elicitation of defense responses and role as salicylic acid precursors. Plant Physiol 125:318-328

Ekiert H, Czygan F-C (2005) Accumulation of biologically active furanocoumarins in agitated cultures of Ruta graveolens $\mathrm{L}$. and Ruta graveolens ssp. divaricata (Tenore) Gams. Pharmazie 60:623-626
Ekiert H, Chołoniewska M, Gomółka E (2001) Accumulation of furanocoumarins in Ruta graveolens L. shoot culture. Biotechnol Lett 23:543-545. https://doi.org/10.1023/A:1010386820799

Ekiert H, Abou-Mandour AA, Czygan F-C (2005) Accumulation of biologically active furanocoumarins in Ruta graveolens ssp. divaricata (Tenore) Gams. in vitro culture. Pharmazie 60:66-68

Ellnain-Wojtaszek M, Zgorka G (1999) High-performance liquid chromatography and thin-layer chromatography of phenolic acids from Ginkgo biloba L. leaves collected within vegetative period. J Liq Chromatogr Relat Technol 22:1457-1471. https:// doi.org/10.1081/JLC-100101744

Fett-Neto AG, Melanson SJ, Nicholson SA et al (1994) Improved taxol yield by aromatic carboxylic acid and amino acid feeding to cell cultures of Taxus cuspidata. Biotechnol Bioeng 44:967971. https://doi.org/10.1002/bit.260440813

Gramazio P, Prohens J, Plazas M et al (2014) Location of chlorogenic acid biosynthesis pathway and polyphenol oxidase genes in a new interspecific anchored linkage map of eggplant. BMC Plant Biol. https://doi.org/10.1186/s12870-014-0350-z

Itoh A, Isoda K, Kondoh M et al (2010) Hepatoprotective effect of syringic acid and vanillic acid on $\mathrm{CCl}_{4}$-induced liver injury. Biol Pharm Bull 33:983-987

Kawka B, Kwiecień I, Ekiert H (2020) Endogenous production of specific flavonoids and verbascoside in agar and agitated microshoot cultures of Scutellaria lateriflora L. and biotransformation potential. Plant Cell Tissue Organ Cult. https://doi. org/10.1007/s11240-020-01837-y

Kawka B, Kwiecień I, Ekiert H (2019) Production of specific flavonoids and verbascoside in shoot cultures of Scutellaria baicalensis. In: Ramawat K, Ekiert H, Goyal S (eds) Plant cell and tissue differentiation and secondary metabolites. Reference series in phytochemistry. Springer, Cham, pp 1-24

Kokotkiewicz A, Jaremicz Z, Luczkiewicz M (2010) Aronia plants: a review of traditional use, biological activities, and perspectives for modern medicine. J Med Food 13:255-269. https://doi. org/10.1089/jmf.2009.0062

Krishnaiah D, Sarbatly R, Nithyanandam R (2011) A review of the antioxidant potential of medicinal plant species. Food Bioprod Process 89:217-233

Kulling SE, Rawel HM (2008) Chokeberry (Aronia melanocarpa)a review on the characteristic components and potential health effects. Planta Med 74:1625-1634. https://doi. org/10.1055/s-0028-1088306

Liu Y, Liu X, Zhong F et al (2011) Comparative study of phenolic compounds and antioxidant activity in different species of cherries. J Food Sci 76:C633-C638. https://doi.org/10.111 1/j.1750-3841.2011.02150.x

Lu D-P, Zhao D-X, Huang Y, Zhao Q (2001) The effect of precursor feeding on flavonoids biosynthesis in cell suspension cultures of Saussurea medusa. Acta Bot Yunn 10:1-3

Matkowski A (2008) Plant in vitro culture for the production of antioxidants-a review. Biotechnol Adv 26:548-560. https://doi. org/10.1016/j.biotechadv.2008.07.001

McCalla DR, Neish AC (1959) Metabolism of phenylpropanoid compounds in salvia: II. biosynthesis of phenolic cinnamic acids. Can J Biochem Physiol 37:537-547. https://doi.org/10.1139/o59-057

Meng S, Cao J, Feng Q et al (2013) Roles of chlorogenic acid on regulating glucose and lipids metabolism: a review. Evid Based Complementary Altern Med 2013:801457. https://doi. org/10.1155/2013/801457

Murashige T, Skoog F (1962) A revised medium for rapid growth and bioassays with tobacco tissue cultures. Physiol Plant 15:473-479

Nakatani N, Kayano S, Kikuzaki H et al (2000) Identification, quantitative determination, and antioxidative activities of chlorogenic acid isomers in prune (Prunus domestica L.). J Agric Food Chem 48:5512-5516. https://doi.org/10.1021/jf000422s 
Natella F, Nardini M, Di Felice M, Scaccini C (1999) Benzoic and cinnamic acid derivatives as antioxidants: structure-activity relation. J Agric Food Chem 47:1453-1459. https://doi.org/10.1021/ jf980737w

Naveed M, Hejazi V, Abbas M et al (2018) Chlorogenic acid (CGA): A pharmacological review and call for further research. Biomed Pharmacother 97:67-74

Ouyang J, Wang XD, Zhao B, Wang YC (2005) Enhanced production of phenylethanoid glycosides by precursor feeding to cell culture of Cistanche deserticola. Process Biochem 40:3480-3484. https ://doi.org/10.1016/j.procbio.2005.02.025

Palacio L, Cantero JJ, Cusidó R, Goleniowski M (2011) Phenolic compound production by Larrea divaricata Cav. plant cell cultures and effect of precursor feeding. Process Biochem 46:418-422. https://doi.org/10.1016/j.procbio.2010.08.029

Parast BM, Chetri SK, Sharma K, Agrawal V (2011) In vitro isolation, elicitation of psoralen in callus cultures of Psoralea corylifolia and cloning of psoralen synthase gene. Plant Physiol Biochem 49:1138-1146. https://doi.org/10.1016/j.plaphy.2011.03.017

Petersen M, Simmonds MSJ (2003) Rosmarinic acid. Phytochemistry 62:121-125. https://doi.org/10.1016/S0031-9422(02)00513-7

Raffauf RF (1983) The Biochemistry of Plants: A Comprehensive Treatise. Volume 7: Secondary Plant Products. P. K. Stumpf. E E Conn. Q Rev Biol 58:438-439. https://doi.org/10.1086/413449

Rosa L, Silva N, Soares N et al (2016) Anticancer properties of phenolic acids in colon cancer-a review. J Nutr Food Sci 06:1-7. https://doi.org/10.4172/2155-9600.1000468

Sajjalaguddam RR, Paladugu A (2015) Phenylalanine enhances quercetin content in in vitro cultures of abutilon indicum L. J Appl Pharm Sci 5:80-84. https://doi.org/10.7324/JAPS.2015.501014

Sato Y, Itagaki S, Kurokawa $\mathrm{T}$ et al (2011) In vitro and in vivo antioxidant properties of chlorogenic acid and caffeic acid. Int J Pharm 403:136-138. https://doi.org/10.1016/j.ijpharm.2010.09.035

Sudhakar Johnson T, Ravishankar GA (1996) Precursor biotransformation in immobilized placental tissues of Capsicum frutescens mill. I. Influence of feeding intermediate metabolites of the capsaicinoid pathway on capsaicin and dihydrocapsaicin accumulation. J Plant Physiol 147:481-485. https://doi.org/10.1016/S0176 $-1617(96) 80035-6$

Sułkowska-Ziaja K, Maślanka A, Szewczyk A, Muszyńska B (2017) Physiologically active compounds in four species of Phellinus. Nat Prod Commun 12:363-366

Szopa A, Ekiert H (2014) Production of biologically active phenolic acids in Aronia melanocarpa (Michx.) Elliott in vitro cultures cultivated on different variants of the Murashige and Skoog medium. Plant Growth Regul 72:51-58. https://doi.org/10.1007/ s10725-013-9835-2

Szopa A, Ekiert H, Muszyńska B (2013) Accumulation of hydroxybenzoic acids and other biologically active phenolic acids in shoot and callus cultures of Aronia melanocarpa (Michx.) Elliott (black chokeberry). Plant Cell Tissue Organ Cult 113:323-329. https:// doi.org/10.1007/s11240-012-0272-0

Szopa A, Kokotkiewicz A, Marzec-Wróblewska U et al (2016) Accumulation of dibenzocyclooctadiene lignans in agar cultures and in stationary and agitated liquid cultures of Schisandra chinensis
(Turcz.) Baill. Appl Microbiol Biotechnol 100:3965-3977. https ://doi.org/10.1007/s00253-015-7230-9

Szopa A, Kokotkiewicz A, Kubica P et al (2017) Comparative analysis of different groups of phenolic compounds in fruit and leaf extracts of Aronia sp.: A. melanocarpa, A. arbutifolia, and $A$. $\times$ prunifolia and their antioxidant activities. Eur Food Res Technol 243:1645-1657. https://doi.org/10.1007/s00217-017-2872-8

Szopa A, Klimek-Szczykutowicz M, Kokotkiewicz A et al (2018a) Phytochemical and biotechnological studies on Schisandra chinensis cultivar Sadova No. 1-a high utility medicinal plant. Appl Microbiol Biotechnol 102:5105-5120. https://doi.org/10.1007/ s00253-018-8981-x

Szopa A, Kubica P, Ekiert H (2018b) Agitated shoot cultures of Aronia arbutifolia and Aronia $\times$ prunifolia: biotechnological studies on the accumulation of phenolic compounds and biotransformation capability. Plant Cell Tissue Organ Cult 134:467-479. https://doi. org/10.1007/s11240-018-1436-3

Szopa A, Kubica P, Snoch A, Ekiert H (2018c) High production of bioactive depsides in shoot and callus cultures of Aronia arbutifolia and Aronia $\times$ prunifolia. Acta Physiol Plant 40:48. https:// doi.org/10.1007/s11738-018-2623-x

Szopa A, Starzec A, Ekiert H (2018d) The importance of monochromatic lights in the production of phenolic acids and flavonoids in shoot cultures of Aronia melanocarpa, Aronia arbutifolia and Aronia $\times$ prunifolia. J Photochem Photobiol B Biol 179:91-97. https://doi.org/10.1016/j.jphotobiol.2018.01.005

Szopa A, Kokotkiewicz A, Klimek-Szczykutowicz M et al (2019) Different types of in vitro cultures of Schisandra chinensis and its cultivar (S. chinensis cv. Sadova): a rich potential source of specific lignans and phenolic compounds. In: Ramawat K, Ekiert H, Goyal S (eds) Plant cell and tissue differentiation and secondary metabolites. Reference series in phytochemistry. Springer, Cham, pp 1-28

Taheri R, Connolly BA, Brand MH, Bolling BW (2013) Underutilized chokeberry (Aronia melanocarpa, Aronia arbutifolia, Aronia prunifolia) accessions are rich sources of anthocyanins, flavonoids, hydroxycinnamic acids, and proanthocyanidins. J Agric Food Chem 61:8581-8588. https://doi.org/10.1021/jf402449q

Thurow T (2012) Effect of chlorogenic acid and neochlorogenic acid on human colon cancer cells. Food Life Sci 13:86-93

van Uden W, Pras N, Vossebeld EM et al (1990) Production of 5-methoxypodophyllotoxin in cell suspension cultures of Linum flavum L. Plant Cell Tissue Organ Cult 20:81-87. https://doi.org/10.1007/ BF00114704

Young IS, Woodside JV (2001) Antioxidants in health and disease. J Clin Pathol 54:176-186

Zhao C, Giusti MM, Malik M et al (2004) Effects of commercial anthocyanin-rich extracts on colonic cancer and nontumorigenic colonic cell growth. J Agric Food Chem 52:6122-6128. https:// doi.org/10.1021/jf049517a

Publisher's Note Springer Nature remains neutral with regard to jurisdictional claims in published maps and institutional affiliations. 